\title{
Survey for Listeria monocytogenes in and on Ready-to-Eat Foods from Retail Establishments in the United States (2010 through 2013): Assessing Potential Changes of Pathogen Prevalence and Levels in a Decade
}

\author{
JOHN B. LUCHANSKY, ${ }^{1}$ YUHUAN CHEN, ${ }^{2 *}$ ANNA C. S. PORTO-FETT, ${ }^{1}$ RÉGIS POUILLOT, ${ }^{2}$ BRADLEY A. SHOYER, ${ }^{1}$ \\ RACHEL JOHNSON-DERYCKE, ${ }^{3 \dagger}$ DENISE R. EBLEN, ${ }^{3 \dagger}$ KARIN HOELZER, ${ }^{2}+$ WILLIAM K. SHAW, JR., ${ }^{3}$ \\ JANE M. VAN DOREN, ${ }^{2}$ MICHELLE CATLIN, ${ }^{3}$ JEEHYUN LEE, ${ }^{4} \S$ ROHAN TIKEKAR, ${ }^{4} \S$ DANIEL GALLAGHER, ${ }^{5}$ \\ JAMES A. LINDSAY, ${ }^{1}$ THE LISTERIA MARKET BASKET SURVEY MULTI-INSTITUTIONAL TEAM,॥ \\ AND SHERRI DENNIS ${ }^{2}$
}

${ }^{1}$ U.S. Department of Agriculture, Agricultural Research Service, Eastern Regional Research Center, 600 East Mermaid Lane, Wyndmoor, Pennsylvania 19038; ${ }^{2}$ U.S. Food and Drug Administration, Center for Food Safety and Applied Nutrition, 5001 Campus Drive, College Park, Maryland 20740; ${ }^{3}$ U.S. Department of Agriculture, Food Safety and Inspection Service, Patriots Plaza III, 1400 Independence Avenue SW, Washington, D.C. 20250; ${ }^{4}$ Department of Food Science, Drexel University, 101 North 33rd Street, Philadelphia, Pennsylvania 19104; and ${ }^{5}$ Department of Civil and Environmental Engineering, Virginia Polytechnic Institute and State University, 409 Durham Hall, Blacksburg, Virginia 24061, USA

MS 16-420: Received 30 September 2016/Accepted 2 January 2017/Published Online 24 April 2017

\begin{abstract}
A multiyear interagency Listeria monocytogenes Market Basket Survey was undertaken for selected refrigerated ready-to-eat foods purchased at retail in four FoodNet sites in the United States. Food samples from 16 food categories in six broad groups (seafood, produce, dairy, meat, eggs, and combination foods) were collected weekly at large national chain supermarkets and independent grocery stores in California, Maryland, Connecticut, and Georgia for 100 weeks between December 2010 and March 2013. Of the 27,389 total samples, 116 samples tested positive by the BAX PCR system for L. monocytogenes, and the pathogen was isolated and confirmed for 102 samples. Among the 16 food categories, the proportion of positive samples (i.e., without considering clustering effects) based on recovery of a viable isolate of L. monocytogenes ranged from $0.00 \%$ (95\% confidence interval: $0.00,0.18)$ for the category of soft-ripened and semisoft cheese to $1.07 \%(0.63,1.68)$ for raw cut vegetables. Among the 571 samples that tested positive for Listeria-like organisms, the proportion of positive samples ranged from $0.79 \%(0.45,1.28)$ for soft-ripened and semisoft cheese to $4.76 \%(2.80,7.51)$ for fresh crab meat or sushi. Across all 16 categories, $L$. monocytogenes contamination was significantly associated with the four states $(P<0.05)$ but not with the packaging location (prepackaged by the manufacturer versus made and/or packaged in the store), the type of store (national chain versus independent), or the season. Among the 102 samples positive for L. monocytogenes, levels ranged from $<0.036$ most probable number per g to $6.1 \log \mathrm{CFU} / \mathrm{g}$. For delicatessen (deli) meats, smoked seafood, seafood salads, soft-ripened and semisoft cheeses, and deli-type salads without meat, the percentage of positive samples was significantly lower $(P<0.001)$ in this survey than that reported a decade ago based on comparable surveys in the United States. Use of mixed logistic regression models to address clustering effects with regard to the stores revealed that L. monocytogenes prevalence ranged from $0.11 \%(0.03,0.34)$ for sprouts (prepackaged) to $1.01 \%(0.58,1.74)$ for raw cut vegetables (prepackaged).
\end{abstract}

Key words: Listeria monocytogenes; Listeria spp.; Market basket survey; Prevalence; Ready-to-eat foods; Retail

\footnotetext{
* Author for correspondence. Tel: 240-402-2290; Fax: 301-436-2633; E-mail: yuhuan.chen@fda.hhs.gov.

$\dagger$ Formerly with the U.S. Department of Agriculture, Food Safety and Inspection Service.

$\ddagger$ Formerly an ORISE fellow with the U.S. Food and Drug Administration.

$\S$ Formerly with Drexel University.

II Members of the Listeria Market Basket Survey Multi-Institutional Team (listed alphabetically): Andrea Adams, ${ }^{1}$ Sally Agnella, ${ }^{1}$ Aimee Aidala, ${ }^{2}$ Dare Akingbade, ${ }^{3}$ Elizabeth G. Baker, ${ }^{1}$ Kristi Barlow, ${ }^{3}$ Nathan Bauer, ${ }^{3}$ Lisa A. Benjamin, ${ }^{4}$ Katrina Berry, ${ }^{1}$ Philip A. Bronstein, ${ }^{3}$ Jeff E. Call, ${ }^{5}$ Stephen G. Campano, ${ }^{6}$ L. Victor Cook,${ }^{3}$ Laura Gathercole, ${ }^{7}$ Deena Ghazzi,${ }^{8}$ Jessica Govoni, ${ }^{9}$ Gregory Hay, ${ }^{7}$ Caitlin Harvey, ${ }^{1}$ Kimberly Hughes,${ }^{2}$ Alisa Kanjanakorn, ${ }^{1}$ Janell Kause, ${ }^{3}$ Sheeri Khokhar, ${ }^{1}$ John King, ${ }^{1}$ Valentina Klein, ${ }^{2}$ Davi LaBarre, ${ }^{3}$ Joanna Lopez, ${ }^{7}$ Karina Martino, ${ }^{1}$ Evelyne Mbandi, ${ }^{3}$ Melissa Murphy, ${ }_{1}$ James Nasella, ${ }^{1}$ Trang Nguyen, ${ }^{1}$ David Oryang, ${ }^{7}$ Manuela Osoria, ${ }^{5}$ Lori Papadakis, ${ }^{7}$ Alice Rajakumar, ${ }^{1}$ China Reed, ${ }^{1}$ Mary Same, ${ }^{7}$ Wayne Schlosser, ${ }^{3 a}$ Laura Shane, ${ }^{2}$ Christopher A. Spurlino, ${ }^{1}$ Holland E. Starks, ${ }^{1}$ Mary Torrence, ${ }^{9}$ Laurie Williams, ${ }^{7}$ Sarah Wadsworth, ${ }^{1}$ and Kelsey Yoo $^{8}$ (affiliations while the survey was conducted: ${ }^{1}$ Drexel University, Philadelphia, PA; ${ }^{2}$ Delaware Valley University, Doylestown, PA; ${ }^{3}$ U.S. Department of Agriculture, Food Safety and Inspection Service, Washington, DC, or ${ }^{3 a}$ College Station, TX; ${ }^{4}$ Western Institute for Food Safety and Security, University of California-Davis, Davis, CA; ${ }^{5}$ U.S. Department of Agriculture, Agricultural Research Service, Wyndmoor, PA; ${ }^{6}$ Hawkins Inc., Roseville, MN; ${ }^{7}$ U.S. Food and Drug Administration, College Park, MD; ${ }^{8}$ Ursinus College, Collegeville, PA; and ${ }^{9}$ U.S. Department of Agriculture, Agricultural Research Service, Beltsville, MD).
} 
Listeria monocytogenes is a major foodborne pathogen with regard to the burden of disease and is a leading cause of mortality attributed to foodborne illness in the United States $(3,22,41)$. This ubiquitous pathogen has the ability to grow or survive at refrigeration temperatures and under conditions of relatively low $\mathrm{pH}$, high salt, and low water activity in numerous foods $(11,12,27,37,39,40)$. L. monocytogenes can be found in a variety of foods, but refrigerated, ready-toeat (RTE) foods, if contaminated with this bacterium, are of particular concern because such products may support the growth of this pathogen and may not be (re)heated prior to consumption $(37,38,56)$. In the United States between 2011 and 2015, at least 17 recalls listed by the U.S. Department of Agriculture, Food Safety and Inspection Service (USDA, FSIS) were due to L. monocytogenes contamination of approximately 1 million pounds $(454,000 \mathrm{~kg})$ of RTE meats (http://www.fsis.usda.gov/Fsis_Recalls/index.asp). In 2015, the U.S. Food and Drug Administration (FDA) listed more than 25 recalls of RTE foods due to contamination with $L$. monocytogenes (http://www.fda.gov/Safety/Recalls/ ArchiveRecalls/2015/default.htm).

To better understand the potential public health impact of L. monocytogenes contamination of RTE foods, many surveys have been conducted to quantify the prevalence and levels of L. monocytogenes in foods. In surveys of approximately 100,000 samples of RTE foods at retail and/or collected at federally inspected plants in the United States between 1990 and 2007, the estimated percentage of samples positive for $L$. monocytogenes was 0.52 to $7.6 \%$ (8, $17,28,37,40,61)$. The comprehensive studies conducted by Gombas et al. (17), Wallace et al. (61), and Draughon (8) wherein the presence or absence of this pathogen was tested for 72,520 RTE food samples either purchased from retail establishments or provided directly by manufacturers revealed pathogen levels of $<0.03$ most probable number $(\mathrm{MPN}) / \mathrm{g}$ to $5.2 \log \mathrm{CFU} / \mathrm{g}$. Since these studies, which were conducted in the early to mid-2000s $(8,17,61)$, no other studies of similar scope or magnitude have been conducted in the United States to determine whether regulatory policies and/or industry practices have made a measurable impact on pathogen prevalence and/or levels in RTE foods, especially those foods previously identified as being of higher risk.

In 2003, the FDA and FSIS in consultation with the Centers for Disease Control and Prevention (CDC) published a quantitative assessment of the relative risk to public health from foodborne L. monocytogenes among 23 selected categories of RTE foods (56). This risk assessment suggested that reformulation of products to reduce the ability to support L. monocytogenes growth was one of several broad mitigation strategies that could reduce the risk of foodborne listeriosis. Data from a four-state study conducted in 2005 and 2006 by the U.S. National Alliance for Food Safety and Security (NAFSS) and reported by Draughon (8) established that the prevalence of $L$. monocytogenes ( $n=8,015)$ was almost eight times greater in delicatessen (deli) meats sliced and packaged at retail $(1.23 \%)$ than in prepackaged deli meats $(0.15 \%)$. Subsequent risk assessments confirmed the public health concern related to L. monocytogenes at delis and suggested that approximately $80 \%$ of illnesses and deaths from listeriosis associated with consumption of deli-type meats are attributable to deli meat sliced at retail facilities (9). Endrikat et al. (9) also estimated that death from listeriosis is 1.7 times more likely from retail-sliced than from prepackaged deli meats. Although additional data for recovery of $L$. monocytogenes from retail deli meats has been published since 2003 (8), corresponding data for other RTE foods, such as cheese, milk, raw fruits, raw vegetables, and deli salads, have not been comprehensively collected since a survey conducted in 2000 and 2001 by the U.S. National Food Processors Association (NFPA) reported by Gombas et al. (17).

Following the publication of the 2003 FDA-FSIS risk assessment, these agencies have published several productspecific risk assessments of the impact of different practices and process interventions on the risk of $L$. monocytogenes from consumption of RTE foods $(46,47,57,58)$. The "FSIS Risk Assessment for Listeria monocytogenes in Deli Meats" (46) provided insight into the relationship between Listeria spp. on food contact surfaces and L. monocytogenes in RTE meat and poultry products and evaluated the effectiveness of food contact surface testing and sanitation regimes, pre- and postpackaging interventions, use of growth inhibitors, and combinations of these interventions to mitigate contamination and reduce the risk of illness or death from $L$. monocytogenes. The FDA-FSIS "Interagency Risk Assessment: Listeria monocytogenes in Retail Delicatessens" (57) assessed the risk of illness associated with RTE foods commonly prepared and sold in the deli of a retail food store and examined how that risk may be impacted by changing common or recommended practices; cross-contamination was found to be important in the retail deli setting. As another example, the "Joint FDA/Health Canada Quantitative Assessment of the Risk of Listeriosis from Soft-Ripened Cheese Consumption in the United States and Canada" (58) evaluated the impact of factors such as the prevalence and levels of L. monocytogenes in raw milk, contamination or manufacturing practices at specific cheese-manufacturing steps, conditions during distribution and storage, and the effectiveness of process changes and intervention strategies for reducing the overall risk of invasive listeriosis to the consumer following the consumption of soft-ripened cheese in the United States and Canada. A primary finding was that consumption of soft-ripened cheese made from raw milk was associated with a 50 to 160 times higher risk of listeriosis per serving compared with otherwise similar cheese made from pasteurized milk.

Both the FDA and FSIS have issued regulations and guidance on risk-based Listeria control (45, 48, 52) following the publication of the 2003 FDA-FSIS risk assessment (56). The food industry has also developed guidance that recommended changes to the way this industry processes and handles RTE products, including increased use of antimicrobial agents and growth inhibitors in the formulation of RTE products and improvements in sanitation and environmental monitoring programs $(16,18,19,23$, 26, 35, 43). Results from monitoring and surveillance suggest that L. monocytogenes contamination in some RTE foods has decreased over the past decade $(9,35,47)$, and 
although substantial amounts of new information have become available, data gaps remain $(20,51)$.

Because of the significant efforts undertaken in the mid2000s by regulators, industry personnel, and academicians to understand and control L. monocytogenes in RTE foods, a well-designed survey was needed to determine whether attendant changes have occurred in the prevalence and levels of this pathogen in RTE foods at retail. Therefore, a multiagency, multidisciplinary survey study (the Interagency Listeria monocytogenes Market Basket Survey) was undertaken to estimate the current prevalence and levels of $L$. monocytogenes in selected categories of deli-packaged and prepackaged RTE foods purchased at retail establishments in four FoodNet sites in the United States. Here, we report the testing results from 16 product categories comprising 27,389 samples. We have focused this report on the analysis of the proportion of L. monocytogenes-positive samples (without consideration of clustering effects), prevalence (with consideration of clustering effects), and levels in each of these 16 food categories. This study also included examination of the association between the prevalence of L. monocytogenes and manufacturing location, store type (national chain versus independent), state, and season and evaluation of the changes in the proportion of positive samples in comparison to related data already published in the United States over a decade ago $(8,17,28,61)$.

\section{MATERIALS AND METHODS}

Selection of RTE product categories. Products from 16 categories within six broad food groups were sampled in this study (Table 1): three categories of seafood (smoked seafood, seafood salads, and fresh crab meat or sushi), three categories of produce (raw cut vegetables, cut low-acid fruits, and sprouts), four categories of dairy (artisanal cheese, soft-ripened and semisoft cheese, cultured milk product, and raw milk), two categories of meat (deli meat and sausage), one category of eggs, and three categories of combination foods (deli-type salad without meat, deli-type salad with meat, and sandwiches). These products were selected based on a number of considerations. The primary focus of the survey was on products that may support L. monocytogenes growth, because those products are reported as contributing to the majority of human listeriosis cases $(13,56)$. Other factors considered included foods in product categories (i) that ranked as medium or high risk; (ii) that had large uncertainty in the ranking in the 2003 FDA-FSIS quantitative risk assessment (56), such as deli meats and fruits; (iii) that had been implicated in human illnesses based on outbreak investigations and case-control studies, such as melon $(14,15,59,60)$; (iv) that had a comparatively high expected prevalence according to previous studies, such as seafood salads (17), which were considered a separate category from delitype salads without meat even though seafood salads can be considered a type of deli salad; and (v) that may have undergone formulation changes by industry since 2003 based on government and industry guidance, such as smoked seafood and deli meats (43, 48,52 ). Products with potentially extensive opportunities for crosscontamination at retail, such as deli-type salads, were also included based on data needs identified in the 2013 interagency risk assessment on L. monocytogenes in retail delicatessens (57). Availability of data from other sources, such as an ongoing survey of pathogens in leafy greens commissioned by the FDA, and the number of samples required to quantify prevalence (a very large number for products with very low expected prevalence such as pasteurized fluid milk) were also taken into consideration in product selections and for estimating the number of samples to be tested for a given food category.

Sampling plan. The sampling plan was stratified according to the following factors: (i) the 16 food categories; (ii) packaging location, i.e., prepackaged by the manufacturer or made at the retail location (deli packaged); (iii) geographic location, including the state and county or city; and (iv) type of retail store (national chain or independent). Only refrigerated RTE products were included in the survey, except for certain cut fruit samples such as papaya, which were sold at room temperature.

All product categories except sprouts, which were sampled on a weekly basis from July 2012 to July 2014, were collected in both national supermarket chain stores and independent grocery stores in California, Maryland, Connecticut, and Georgia on a weekly basis for 100 weeks from December 2010 to March 2013. National chain stores were defined as having $>10$ stores in the brand, with each location having a deli that sliced or cut products such as deli meat and cheese. Independent regional stores were defined as having $<10$ stores in the brand and being located in no more than two states, with each location having a deli that sliced or cut products such as deli-type meat and cheese. Some products were also purchased from supplemental stores, which did not have a deli but did carry specialty items such as prepackaged smoked seafood and soft cheese. Raw milk was available at some retail stores in California and Connecticut only.

Target number of samples. For each selected food category, the target number of samples was estimated based on published data on L. monocytogenes prevalence and desired statistical power, using the formula and method described by Gombas et al. (17). For example, if $2.4 \%$ of deli salad samples were to test positive for the pathogen, 1,278 samples would be needed to obtain a desired $35 \%$ precision for the prevalence estimate, with an expected 30 positive samples for this category. The desired precision was selected to obtain sufficient numbers of positive samples to characterize the distribution of contamination levels (CFU per gram) for these product categories, which is necessary for a risk assessment. Because data on the variability in L. monocytogenes levels are important for characterizing risk to the consumer, 30 positive samples were initially targeted. The expected proportion of positive samples for the selected categories was made based on published data $(17,29,30,32)$ and on unpublished data and judgments from the survey team. A larger number of samples was targeted (e.g., based on $35 \%$ instead of $50 \%$ precision) to allow for a more precise estimate of prevalence even if the percentage of positive samples in some food categories were confirmed as lower than that assumed. Supplemental Table S1 shows examples of the target number of samples for various food categories and the experimental matrix for the present study.

Table 1 is a list of specific food types within a food category and the target sampling percentages for all 16 food categories. Each RTE product category typically contained multiple food types, for a total of over 40 food types within the 16 food categories (see Table 1). The sampling percentage for each individual food type within a food category was determined based on an evaluation of consumption data. The consumption data included the fractions of the population consuming a food as estimated from the National Health and Nutrition Examination Survey What We Eat in America database (1999 through 2006; http://www.ars.usda.gov/services/docs.htm?docid=13793) and industry production data (e.g., for smoked seafood). The selected products in this study overlapped in part and by design with those 


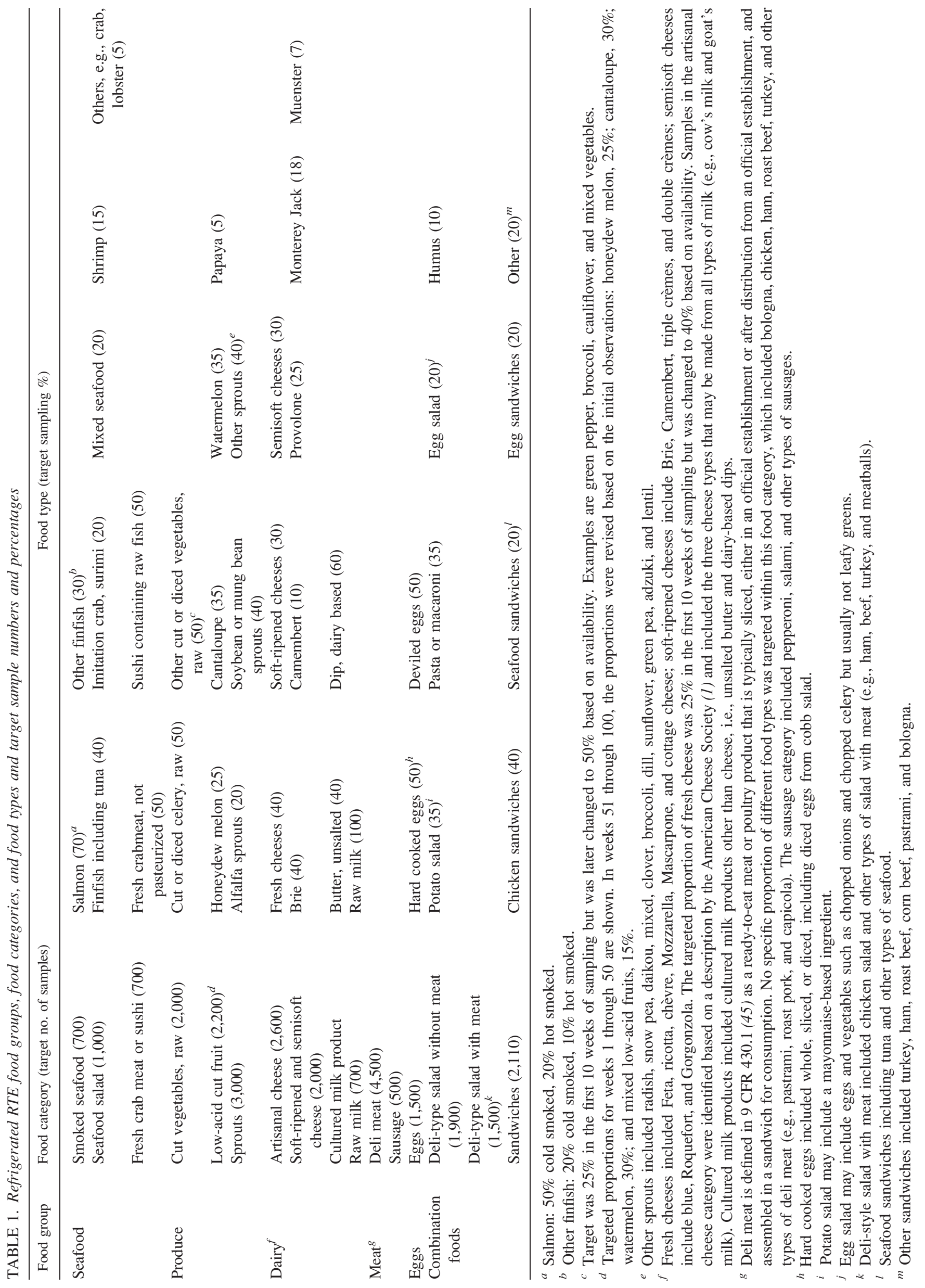


included in the 2000 to 2001 NFPA survey of eight RTE product categories reported by Gombas et al. (17) to facilitate evaluation of potential changes.

Sampling locations within FoodNet sites and selection of retail stores. The sampling sites were located in locations in Maryland, Connecticut, Georgia, and northern California where the CDC conducts active surveillance for listeriosis through the Foodborne Diseases Active Surveillance Network (FoodNet; http://www.cdc.gov/foodnet), thus potentially allowing exposure data and food isolates to be related to illness data and clinical isolates. Surveillance as part of FoodNet is statewide in Maryland, Connecticut, and Georgia, but in California FoodNet sites cover San Francisco, Alameda, and Contra Costa counties. In the NFPA survey (17), RTE food samples were collected in the California and Maryland FoodNet sites allowing comparison of prevalence and enumeration data between the NFPA survey and the present study for many of the same product types sampled about a decade apart. The present survey covered all counties in the Connecticut and northern California FoodNet sites, the 10 most populated cities and/or counties in Maryland, and four metropolitan locations in Georgia (Athens, Savannah, and two counties in the Atlanta metropolitan area).

Samples were collected from national chain and independent retail stores that had a deli to allow for sampling of a variety of products (brand-name and unbranded products) representative of what the consumer could purchase and consume in these areas. The results from this survey were blind to the name of product brand and the name of the store in which the samples were collected. For certain specialty products, such as smoked seafood and soft cheese, supplemental retail stores that did not have a deli were also used. In California and Connecticut, retail stores that sold raw milk were visited to purchase raw milk (this product was not available in Maryland and Georgia). See the Supplemental Materials section "Further Description of the Sampling Design" for details on the selection of sampling locations (counties and cities) within the FoodNet sites and the selection of retail stores within counties and cities. Supplemental Table S2 provides more details on the store definitions, the number of stores visited, and the specific weeks in which samples were collected for each of the 16 food categories.

Collection of samples. A weekly shopping list was generated in advance and used for the sample collection trip (see an example in Supplemental Table S3). Approximately 150 to 200 samples of FDA-regulated products and a similar number of FSIS-regulated products were purchased from retail stores in alternating weeks in California, Maryland, Connecticut, and Georgia. Usually, in each week when both FDA- and FSIS-regulated products were collected, the total was adjusted to no more than 300 samples to accommodate laboratory capacity. On occasion, shoppers visited a store that was not originally listed but that was along the driving route in the targeted location; in this case, the store was verified as fitting the definition of the targeted store type (Supplemental Table $\mathrm{S} 2$ ), and these data were coded accordingly as part of the metadata collected.

The number of samples to be tested each week was based on the sampling percentage for the food type, store type, and ratio of prepackaged versus deli-packaged products. The target ratio of the number of samples from national chain stores versus local independent stores was 3:1, which is the same target ratio used in the NFPA survey (17) to represent consumer shopping patterns. The target ratio of products prepackaged by a manufacturer versus sliced, prepared, or packaged in a retail deli was 2:1 for raw cut vegetables, 1:2 for deli-type salads without meat, and 1:1 for seafood salads, sushi, cultured milk products (cheese-based dips), low-acid cut fruits, eggs, and soft-ripened and semisoft cheese to represent to some degree estimated proportions available to consumers. For smoked seafood, fresh crab meat or sushi, sprouts, cultured milk products (unsalted butter), and raw milk, only prepackaged products were purchased because these were the type of products expected to be available at retail stores. For sandwiches, deli-type salads with meat, deli meat, and sausage, only deli-prepared products were targeted for purchase. For artisanal cheeses, products were purchased based on availability, which was generally prepackaged products available for purchase online and a mixture of prepackaged and deli-sliced or -packaged products purchased at retail stores.

Shoppers were instructed to purchase unique samples, i.e., to avoid collecting two similar deli-sliced or deli-prepared products in the same store or two prepackaged products of the same brand in the same store. Detailed sample collection instructions were developed and used for the shopping trips. The information provided included product category (e.g., cheese), specific types of products included in the category (e.g., Brie), the number of samples of each type of product within the category, the size of the sample to be purchased ( 8 to $16 \mathrm{oz}$ [ 227 to $453 \mathrm{~g}$ ] or two packages of the same code if only a $<8$-oz package was available), and what products were included (refrigerated and RTE) or excluded (e.g., shelf stable or frozen). Shoppers measured the product surface temperature at the time of purchase and placed a temperature data logger in the coolers for shipping to the USDA Agricultural Research Service (ARS) laboratory (Wyndmoor, PA) (unpublished data). Products (except sprouts) purchased in Maryland and Connecticut were driven by shopper(s) back to the ARS laboratory, usually on the same day as purchased or the next day. Products purchased in California and Georgia were shipped to the ARS laboratory via overnight carrier. Sprout samples were transported similarly by car or via overnight carrier to a third-party laboratory in the United States for testing.

Handling of samples upon receipt and recording of metadata. Samples were examined upon arrival at the laboratory in a designated room that was on a floor separate from where the samples were prepared and tested for L. monocytogenes. This separation further reduced the likelihood of inadvertent contamination of food samples in the laboratory and maintained confidentiality of the brands being tested. In rare cases in which the sample package was damaged such that the microbiological integrity of the sample might have been compromised or if the sample collected did not meet the description for the product category, the sample was discarded and the reason was noted in the study records.

Each sample was assigned a unique letter-number code and the following information was recorded: (i) product category and food type within the category, (ii) sampling state location, (iii) date of purchase in store and date of receipt at the laboratory, (iv) whether the sample appeared to be packaged or prepared in the store (deli packaged) or was in the original manufacturer's packaging (prepackaged), (v) the type of store (national chain, independent or local, or milk store), (vi) the surface temperature of product at time and place of purchase plus shipping cooler identification and associated data logger temperature profile(s), (vii) the temperature of a representative number of food samples within each cooler when it arrived and was opened (usually two products from the bottom, one from the middle, and two from the top of the cooler), and (viii) shopper identification and notes (if any). Temperature data will be reported in a separate article. 
The laboratory personnel aseptically transferred samples into individual sterile plastic Whirl-Pak bags (Nasco, Salida, CA). Information on the product label for each sample was recorded: the list of ingredients, the sell-by or use-by date as available, and whether the product was domestic or imported. The samples were stored at $4 \pm 2^{\circ} \mathrm{C}$ until the initiation of microbial testing, usually the next day or within 2 to 3 days after receipt. Samples were usually received on a Friday via overnight carrier or on occasion during the weekend (i.e., for Connecticut and Maryland when shoppers transported food samples directly to the laboratory).

Testing procedures. With the exception of sprouts, which were analyzed by the third-party laboratory, all samples were analyzed at the ARS laboratory (Wyndmoor, PA) for the presence and levels of L. monocytogenes using procedures developed according to detection and isolation methods described in the FDA Bacteriological Analytical Manual (54), the FSIS revised Microbiological Laboratory Guide (49), or the 2000 to 2001 NFPA survey (17). Each sample was divided into several portions. One portion $(25 \pm 0.2 \mathrm{~g}$ ) was used for screening for the presence or absence of L. monocytogenes. A second portion ( 350 to $425 \mathrm{~g}$ ) was refrigerated $\left(4^{\circ} \mathrm{C}\right)$ for 7 to 10 days but in some instances for up to 14 days for enumeration of the pathogen in samples testing positive in the screening step. Another portion (about $250 \mathrm{~g}$ ) was stored frozen for subsequent analyses of intrinsic parameters affecting microbial viability in foods (e.g., $\mathrm{pH}$, water activity, and concentrations of selected antimicrobial agents or preservatives). The remainder of the sample was retained at $-20^{\circ} \mathrm{C}$ for possible subsequent testing as appropriate. Part of the study design was to purchase samples that were available to the general public at retail; thus, products were at various stages of the anticipated shelf life. Shoppers purchased foods for testing that were well within their stated sell-by or best-if-used-by dates on the product label.

As part of the screening process, the presence or absence of Listeria-like organisms (LLO) was determined using traditional Listeria enrichment and isolation media (54), which test for microorganisms with biochemical characteristics typical for but not exclusive to Listeria spp. (48). L. monocytogenes isolates confirmed by culture methods were obtained from either the screening or the enumeration step. Supplemental Figure S1 provides an overview of the testing procedures. The testing for LLO was included in the survey because these organisms are an indicator for L. monocytogenes and are usually more likely to be detected than L. monocytogenes. Testing for these organisms in the food processing and handling environments (postlethality steps) has been recommended as part of a comprehensive Listeria control program to verify sanitation and to indicate whether conditions are also suitable for survival and/or growth of L. monocytogenes. However, data are lacking on the concurrence of LLO and $L$. monocytogenes in the same environmental or food samples, and collecting such data in this study would help fill this gap.

Sample screening. For pathogen screening, $25 \pm 0.2 \mathrm{~g}$ of the sample was aseptically transferred to a sterile stomacher bag and mixed with $225 \mathrm{~mL}$ of buffered Listeria enrichment broth base containing sodium pyruvate without selective agents (basal BLEB). The mixture was homogenized by stomaching for $2 \mathrm{~min}$ in a Stomacher 400 circulator (Seward, Worthing, UK) to ensure mixing of the sample component with the enrichment broth. The FDA previously validated the enrichment method with BLEB for a 25 -g sample portion (i.e., $10 \%$ food matrix in enrichment broth) for a variety of products (54); detection sensitivity was equivalent to 1 $\mathrm{CFU}$ in $25 \mathrm{~g}$. The $250-\mathrm{mL}$ basal BLEB-product mixture was incubated at $30^{\circ} \mathrm{C}$ for $4 \pm 0.2 \mathrm{~h}$, and then selective agents (i.e.,

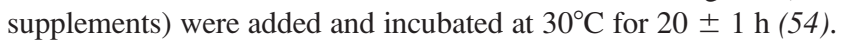

The enrichment culture was mixed well, and $1 \mathrm{~mL}$ was transferred to $9 \mathrm{~mL}$ of BLEB with selective agents (i.e., BLEB base supplements) and incubated at $35^{\circ} \mathrm{C}$ for $24 \pm 2 \mathrm{~h}$. The BAX PCR system for L. monocytogenes (BAX System Q7, DuPont Qualicon, Wilmington, DE) was used to individually screen the enrichment culture for each sample according to the manufacturer's instructions. A portion of the enrichment culture was also streaked onto Oxford agar (OXA; BD, Sparks, MD) plates, which were incubated at $35^{\circ} \mathrm{C}$ for $48 \mathrm{~h}$ and examined for distinctive 1- to 2mm-round colonies surrounded by a black halo, a morphology typical of Listeria spp. $(17,49,54)$. When such colonies were present in a sample culture, the sample was designated as positive for LLO, and plates were held for subsequent confirmation.

When the sample tested negative with the BAX PCR system, confirmation would be conducted only when the enrichment culture OXA plate displayed typical Listeria colonies. When the sample tested positive with the BAX PCR system, the retained portion of the sample was used for pathogen enumeration with confirmation. Each of the positive samples was enumerated by both the MPN method $(53,54)$ and the direct plate count method (17). Detailed procedures for these methods and associated results may be reported elsewhere for the determination of the distribution of pathogen levels. To accommodate the extra workload, sprout samples were tested by a third-party laboratory. A 25 -g portion was analyzed for the presence of $L$. monocytogenes by using the AOAC official method 2003.12 (2), for which screening was performed by using the BAX PCR system for L. monocytogenes. For samples that tested positive for the pathogen, a retained portion of the sample was used for enumeration according the FDA Bacteriological Analytical Manual methods $(53,54)$.

Isolation and confirmation of $\boldsymbol{L}$. monocytogenes. Suspected L. monocytogenes colonies displaying $\beta$-hemolysis on horse blood agar (Remel, Lenexa, KS) were individually streaked for purity on Trypticase soy agar with yeast extract (TSAYE; BD). A clearly isolated colony on TSAYE was then subjected to further biochemical confirmation using the API Listeria ID strip (bioMérieux, Hazelwood, MO) according to the manufacturer's instructions. When a colony was confirmed to be L. monocytogenes, all of the $\beta$-hemolytic colonies from the same sample were considered to be L. monocytogenes. When a colony was confirmed as not L. monocytogenes, up to two additional $\beta$-hemolytic colonies were processed for confirmation using the API method. When all three colonies were confirmed as not $L$. monocytogenes, none of the $\beta$-hemolytic colonies from the sample were considered to be L. monocytogenes. Up to 10 clearly isolated $\beta$-hemolytic colonies (obtained from one positive food sample) were retained and subjected to further analysis for L. monocytogenes confirmation. Upon confirmation, L. monocytogenes isolates were retained (usually two or more isolates for each positive sample).

Quality controls for laboratory testing. The L. monocytogenes strain F2365 was used as a positive control (34), Listeria innocua Seeliger (ATCC 33090) was used as a negative control, and sterile BLEB was used as a blank control; controls were tested each week using the BAX PCR system followed by confirmation tests (including blood agar culture and API). Laboratory environmental monitoring of approximately 30 sample contact surfaces, sample noncontact surfaces, and personal equipment in each laboratory was conducted during sample preparation and analysis. Eight to 10 surfaces and/or pieces of equipment within our laboratories were tested each week at random during the 100- 
week study. The surfaces and equipment were swabbed and tested for L. monocytogenes using the enrichment process followed by the BAX PCR system and OXA plating.

During the entire study, approximately 990 environmental samples from about 30 sites in two laboratory locations (rooms) were obtained, and only 1 sample tested positive for $L$. monocytogenes; however, no food sample tested positive for the pathogen during that specific sampling week. After appropriate corrective measures, the contaminated site was retested, and the results were negative for $L$. monocytogenes by both the BAX assay and OXA plating. Data from the environmental samples and from the negative and positive controls confirmed that no laboratory contamination of the RTE food samples tested occurred and that the microbiological media and/or recovery or detection methods used worked accurately.

Data analysis. Each sample was identified by a unique sample identifier that was used to connect product and ingredient information (metadata) and microbial testing data for the sample. The metadata and the microbial testing data were cross-checked through multiple iterations to verify accuracy, including to ensure the absence of duplicate entries. The metadata were used to classify the tested samples into product categories by state, store type, season, and manufacturing location.

The proportion of positive samples was compared using Fisher's exact test and Cochran-Mantel-Haenszel statistics, as implemented in the SAS software package (v. 9.4, SAS Institute, Cary, NC). The proportion of positive samples was analyzed using Fisher's test to determine whether there was an overall difference among the 16 food categories with regard to contamination by $L$. monocytogenes and LLO. Given that sampling was stratified by state, type of store, and manufacturing location, Fisher's test was used to compare the proportion of positive samples by food category and state, by food category and manufacturing location, and by food category and store type, where $P \leq 0.05$ indicates a significant difference. The Cochran-Mantel-Haenszel test was used to determine whether in general across all 16 food categories, the proportion of positive samples was different with regard to the state, location, or store type.

For L. monocytogenes, prevalence estimates for the food categories and statistical comparisons were made using logistic regression models to allow for consideration of the stratification in the study design and potential clustering effects. L. monocytogenes contamination within stores was evaluated using a fixed-effect model that did not take into account spatial correlations (hereinafter referred to as random effect not considered) and a mixed logistic regression model that explicitly accounted for store correlation (hereinafter referred to as random effect considered). The food category and the manufacturing location (deli packaged versus prepackaged) were parameters of interest in the models.

Both the fixed-effect and the mixed-effect models were used to estimate the prevalence of $L$. monocytogenes and to test differences in prevalence estimates with regard to food categories and manufacturing locations where appropriate. The impacts of the type of store (e.g., national chain versus independent stores), the state, and the season were also evaluated. The impact of the type of store and the season were not significant $(P>0.2)$; the inclusion of the store and the season did not change the prevalence estimates, and these variables were thus removed from the model. The state variable was kept in the models because it was used as a stratum in the sampling plan and because it was significant at $P<0.2$. The estimates from the mixed models used state as a random effect, with store nested within state. All the generalized linear models (specifically mixed logistic regression models) were developed with the glimmix procedure available in the SAS software. The two-tailed Fisher's exact test was used to compare the proportion of positive samples in selected product categories obtained in this survey with the values estimated in the NAFSS survey (8) and the NFPA survey conducted a decade ago (17); this comparison was feasible because of the similarity in study design and product categories among the these three studies.

\section{RESULTS AND DISCUSSION}

L. monocytogenes has consistently garnered regulatory attention over the past 25 years because of the severity and mortality associated with listeriosis, the general condition and increasing number of susceptible members of the population, and the frequency and magnitude of product recalls. Although this pathogen can be eliminated from RTE products during processing, it can be reintroduced onto the surface of RTE foods when the finished product is exposed to the food processing environment before packaging and/or during further handling at the retail location or in the home $(33,37-39)$. Because of the potential for cross-contamination of L. monocytogenes harbored in niches in the food processing and retail environments, we conducted a retail survey of 16 food categories to estimate the prevalence of $L$ monocytogenes in these foods. Over a 2-year period, 27,389 food samples were collected at grocery stores to quantify pathogen levels in samples testing positive and to obtain isolates for subtyping $(5,31)$.

Number of stores visited. Most of the 27,389 food samples were collected from unique stores, although some of the stores were visited more than once (in different weeks; see Supplemental Table S2 for details). Among the 1,042 store visits during the 100 weeks, 593 visits were to national chain stores, 292 visits were to independent regional stores, and 59 visits were to supplemental stores. Raw milk samples were collected during 98 visits to retail raw milk stores in California and Connecticut and from some of the independent stores that offered raw milk for sale. Artisanal cheeses were purchased, when available, from stores and from online retailers obtained from a list of over 100 cheesemakers or brokers offering products for sale via the Internet.

Number of samples harboring presumptive or confirmed L. monocytogenes. Of the 27,389 samples, 116 tested positive for L. monocytogenes by the BAX PCR system (Table 2), and the pathogen was isolated from 102 of these samples (Table 3). Table 2 shows the number of samples collected for each category, the number of samples that were positive for L. monocytogenes with the BAX PCR system, the percentage of positive samples, and the $95 \%$ exact confidence interval (CI). Table 3 shows the number of samples from which $L$. monocytogenes isolates were obtained and the number of samples from which colonies displaying morphology typical of Listeria spp. were recovered from enrichment cultures streaked onto OXA agar plates, i.e., LLO. We use LLO hereinafter to represent colonies recovered on OXA, which may include Listeria spp. and LLO because no further confirmation of the colony identity (beyond the confirmation test specific for $L$. 
TABLE 2. Detection of presumptive L. monocytogenes in RTE foods using the BAX PCR system as a screening test

\begin{tabular}{|c|c|c|c|c|}
\hline \multirow[b]{2}{*}{ Food group } & \multirow[b]{2}{*}{ Food category } & \multirow[b]{2}{*}{ Total no. of samples } & \multicolumn{2}{|c|}{ BAX-positive samples ${ }^{a}$} \\
\hline & & & No. & $\%(95 \% \mathrm{CI})$ \\
\hline \multirow[t]{3}{*}{ Seafood } & Smoked seafood & 745 & 2 & $0.27(0.03,0.97)$ \\
\hline & Seafood salad & 993 & 10 & $1.01(0.48,1.84)$ \\
\hline & Fresh crab meat or sushi & 357 & 0 & $0.00(0.00,1.03)$ \\
\hline \multirow[t]{3}{*}{ Produce } & Cut vegetables, raw & 1,689 & 19 & $1.12(0.68,1.75)$ \\
\hline & Low-acid cut fruit & 2,408 & 12 & $0.50(0.26,0.87)$ \\
\hline & Sprouts & 2,652 & 5 & $0.19(0.06,0.44)$ \\
\hline \multirow[t]{4}{*}{ Dairy } & Artisanal cheese & 2,437 & 5 & $0.21(0.07,0.48)$ \\
\hline & Soft-ripened and semisoft cheese & 2,028 & 1 & $0.05(0.00,0.27)$ \\
\hline & Cultured milk product & 468 & 1 & $0.21(0.01,1.18)$ \\
\hline & Raw milk & 477 & 3 & $0.63(0.13,1.83)$ \\
\hline \multirow[t]{2}{*}{ Meat } & Deli meat & 5,917 & 15 & $0.25(0.14,0.42)$ \\
\hline & Sausage & 571 & 1 & $0.18(0.00,0.97)$ \\
\hline Eggs & Eggs & 456 & 0 & $0.00(0.00,0.81)$ \\
\hline \multirow[t]{3}{*}{ Combination foods } & Deli-type salad without meat & 2,457 & 23 & $0.94(0.59,1.40)$ \\
\hline & Deli-type salad with meat & 1,415 & 4 & $0.28(0.08,0.72)$ \\
\hline & Sandwiches & 2,319 & 15 & $0.65(0.36,1.06)$ \\
\hline Total & & 27,389 & 116 & \\
\hline
\end{tabular}

${ }^{a}$ Enrichment culture from screening step for each sample was tested using the BAX L. monocytogenes PCR system. Some of the BAXpositive samples did not yield L. monocytogenes in the culture confirmation step, e.g., 2 of the 15 deli meat samples did not yield an $L$. monocytogenes isolate. CI, confidence interval.

monocytogenes) was performed. Strictly defined, LLO colonies resemble Listeria strains when cultured on Listeria-selective agars and are gram positive and catalase positive similar to Listeria, but unlike Listeria these colonies do not exhibit the typical umbrella-shaped motility. Whereas cells of L. monocytogenes are pathogenic for humans, Listeria spp. and LLO (with the exception of Listeria ivanovii, which is an opportunistic human pathogen) are not likely to cause foodborne listeriosis.

Samples testing positive by the BAX PCR system did not always yield an L. monocytogenes isolate; the pathogen was isolated from only 102 of the 116 BAX-positive samples. For one smoked seafood sample and two deli meat samples that tested negative with the BAX PCR system, colonies were recovered from enrichment culture streaked on OXA and were subsequently confirmed as L. monocytogenes. For the three meat categories, the number of BAX-positive samples subsequently confirmed by recovery of a viable isolate of $L$. monocytogenes was 13 of 15 for deli meat (total 5,917 samples), 1 of 1 for sausage (total 571), and 4 of 4 for delitype salad with meat (total 1,415). Among all 16 food categories, the proportion $(95 \% \mathrm{CI})$ of samples positive for $L$. monocytogenes in a specific category ranged from $0.00 \%$ $(0.00,0.18)$ for soft-ripened and semisoft cheese to $1.07 \%$ $(0.63,1.68)$ for raw cut vegetables. Raw milk was listed as an ingredient for two soft-ripened and semisoft cheese samples and three artisanal cheese samples; none were positive for $L$. monocytogenes. Pathogen levels across all positive samples ranged from $<0.036 \mathrm{MPN} / \mathrm{g}$ to $6.1 \mathrm{log} \mathrm{CFU} / \mathrm{g}$. Summary results on $L$. monocytogenes levels by food category are presented in Table 4. These levels likely represent the levels of the pathogen in the products at purchase and possibly growth that might have occurred during shipping to the laboratory and subsequent storage before enumeration. The samples were stored in a well-controlled laboratory incubator $\left(4 \pm 1^{\circ} \mathrm{C}\right.$ ); thus, expected growth during storage (usually 7 to 10 days) would be low and could vary depending on the product characteristics. According to the analysis in the 2003 FDA-FSIS risk assessment (56), the majority of the predicted listeriosis cases associated with postretail pathogen growth was attributed to consumer storage at temperatures above $5^{\circ} \mathrm{C}$. Further analysis of the distribution of pathogen levels in the context of product time and temperature, product characteristics (e.g., pH and water activity), and other factors will be reported in a separate article.

Colonies of LLO were recovered from 571 samples in 15 of the 16 categories (Table 3); LLO was not tested for sprout samples. Among all 16 categories, the proportion of samples $(95 \% \mathrm{CI})$ positive for LLO in a specific category ranged from $0.79 \%(0.45,1.28)$ for the soft-ripened and semisoft cheese category to $4.76 \%(2.80,7.51)$ for the fresh crab meat and sushi category. As expected, the number of samples testing positive for LLO was higher than that for $L$. monocytogenes across all the 15 categories, e.g., 71 samples positive for LLO versus 21 for L. monocytogenes for delitype salad without meat (i.e., multicomponent products such as egg salad, pasta salad, potato salad, and humus from a total of 2,457 samples) and 16, 17, and 10 positive for LLO versus 0 for L. monocytogenes for soft-ripened and semisoft cheese (total of 2,028 samples), fresh crab meat and sushi (total of 357 samples), and eggs (total of 456 samples), respectively. Although one soft-ripened or semisoft cheese sample was positive with the BAX PCR, none of the LLO recovered from that sample were confirmed as $L$. monocytogenes. As expected, the number of samples testing positive for LLO was also higher than that for L. monocytogenes in the meat-containing categories: 138 versus 15,13 versus 1 , and 47 versus 4 for deli meat, sausage, and deli-type salad 
TABLE 3. Detection of L. monocytogenes and Listeria-like organisms in RTE foods

\begin{tabular}{|c|c|c|c|c|}
\hline Food group & Food category & Total no. of samples & No. of positive samples ${ }^{a}$ & $\%$ positive samples $(95 \% \mathrm{CI})$ \\
\hline \multicolumn{5}{|c|}{ L. monocytogenes isolates confirmed by culture } \\
\hline \multirow[t]{3}{*}{ Seafood } & Smoked seafood & 745 & $3^{b}$ & $0.40(0.08,1.17)$ \\
\hline & Seafood salad & 993 & 9 & $0.91(0.42,1.71)$ \\
\hline & Fresh crab meat or sushi & 357 & 0 & $0.00(0.00,1.03)$ \\
\hline \multirow[t]{3}{*}{ Produce } & Cut vegetables, raw & 1,689 & 18 & $1.07(0.63,1.68)$ \\
\hline & Low-acid cut fruit & 2,408 & 9 & $0.37(0.17,0.71)$ \\
\hline & Sprouts & 2,652 & 3 & $0.11(0.02,0.33)$ \\
\hline \multirow[t]{4}{*}{ Dairy } & Artisanal cheese & 2,437 & 4 & $0.16(0.04,0.42)$ \\
\hline & Soft-ripened and semisoft cheese & 2,028 & 0 & $0.00(0.00,0.18)$ \\
\hline & Cultured milk product & 468 & 1 & $0.21(0.01,1.18)$ \\
\hline & Raw milk & 477 & 3 & $0.63(0.13,1.83)$ \\
\hline \multirow[t]{2}{*}{ Meat } & Deli meat & 5,917 & $15^{b}$ & $0.25(0.14,0.42)$ \\
\hline & Sausage & 571 & 1 & $0.18(0.00,0.97)$ \\
\hline Eggs & Eggs & 456 & 0 & $0.00(0.00,0.81)$ \\
\hline \multirow[t]{3}{*}{ Combination foods } & Deli-type salad without meat & 2,457 & 21 & $0.85(0.53,1.30)$ \\
\hline & Deli-type salad with meat & 1,415 & 4 & $0.28(0.08,0.72)$ \\
\hline & Sandwiches & 2,319 & 11 & $0.47(0.24,0.85)$ \\
\hline \multirow[t]{2}{*}{ Total } & & 27,389 & 102 & \\
\hline & & eria-like organisms & & \\
\hline \multirow[t]{3}{*}{ Seafood } & Smoked seafood & 745 & 17 & $2.28(1.33,3.63)$ \\
\hline & Seafood salad & 993 & 32 & $3.22(2.21,4.52)$ \\
\hline & Fresh crab meat or sushi & 357 & 17 & $4.76(2.80,7.51)$ \\
\hline \multirow[t]{3}{*}{ Produce } & Cut vegetables, raw & 1,689 & 38 & $2.25(1.60,3.08)$ \\
\hline & Low-acid cut fruit & 2,408 & 53 & $2.20(1.65,2.87)$ \\
\hline & Sprouts & 2,652 & $\mathrm{NA}^{c}$ & \\
\hline \multirow[t]{4}{*}{ Dairy } & Artisanal cheese & 2,437 & 41 & $1.68(1.21,2.28)$ \\
\hline & Soft-ripened and semisoft cheese & 2,028 & 16 & $0.79(0.45,1.28)$ \\
\hline & Cultured milk product & 468 & 6 & $1.28(0.47,2.77)$ \\
\hline & Raw milk & 477 & 14 & $2.94(1.61,4.88)$ \\
\hline \multirow[t]{2}{*}{ Meat } & Deli meat & 5,917 & 138 & $2.33(1.96,2.75)$ \\
\hline & Sausage & 571 & 13 & $2.28(1.22,3.86)$ \\
\hline Eggs & Eggs & 456 & 10 & $2.19(1.06,4.00)$ \\
\hline \multirow[t]{3}{*}{ Combination foods } & Deli-type salad without meat & 2,457 & 71 & $2.89(2.26,3.63)$ \\
\hline & Deli-type salad with meat & 1,415 & 47 & $3.32(2.45,4.39)$ \\
\hline & Sandwiches & 2,319 & 58 & $2.50(1.90,3.22)$ \\
\hline Total & & 27,389 & 571 & \\
\hline
\end{tabular}

${ }^{a}$ Enrichment culture from the screening step for each sample was streaked on Oxford agar, which recovered colonies with morphology typical of Listeria spp. (i.e., Listeria-like organisms) and were then subject to confirmation.

${ }^{b}$ One of the smoked seafood samples and two of the deli meat samples were negative by the BAX PCR system but positive for $L$. monocytogenes by culture.

${ }^{c}$ NA, not applicable (data not available).

with meat, respectively. The recovery of LLO from enrichment cultures following screening for L. monocytogenes via the BAX PCR system or OXA culture may negatively impact the ability to recover pathogenic species or serotypes of Listeria. Keys et al. (25) reported that $L$. innocua appreciably outcompeted serotype $4 \mathrm{~b}$ isolates of $L$. monocytogenes by $\leq 2 \log \mathrm{CFU} / \mathrm{mL}$ in enrichment culture after incubation at $30^{\circ} \mathrm{C}$ for $48 \mathrm{~h}$. Higher levels of L. innocua than L. monocytogenes could make it more difficult to recover the latter from food products and, in turn, result in an elevated rate of false-negative results.

Percentage of samples positive for $L$. monocytogenes by state, store type, and packaging location. Table 5 presents the percentage of samples positive for L. monocy- togenes by product category and by state. There was a significant difference in the percentage of L. monocytogenes-positive samples per state in six categories: raw cut vegetables, low-acid cut fruit, artisanal cheese, raw milk, deli meat, and deli-type salad without meat. This difference might reflect differences among the states in product origins, store environments, and other factors such as food safety practices. Among all 16 categories, the overall association between percentage of samples positive for L. monocytogenes and the state was significant $(P=0.0001)$ after adjusting for the various food categories (Table 5). In contrast, the overall association between percentage of samples positive for LLO and the state was not significant, even though a significant difference was found for 7 of the 16 product categories (Supplemental Table S4). 
TABLE 4. Levels of L. monocytogenes detected in various food categories when a confirmed isolate was obtained

\begin{tabular}{lll}
\hline \multicolumn{1}{c}{ Food group } & \multicolumn{1}{c}{ Food category } & L. monocytogenes $\left(\mathrm{MPN} / \mathrm{g}\right.$ or CFU/g) $^{a}$ \\
\hline Seafood & Smoked seafood & $9-250$ \\
& Seafood salad & $<0.036-120$ \\
& Fresh crab meat or sushi & NA \\
Produce & Cut vegetables, raw & $<0.036-330$ \\
& Low-acid cut fruit & $<0.036-0.9$ \\
Dairy & Sprouts & $<0.036-1.1 \times 10^{3}$ \\
& Artisanal cheese & $<0.036-1.4 \times 10^{6}$ \\
& Soft-ripened and semisoft cheese & NA \\
Meat & Cultured milk product & $<0.036$ \\
& Raw milk & $0.9-40$ \\
Eggs & Deli meat & $<0.036-1.1 \times 10^{4}$ \\
Combination foods & Sausage & $<0.036$ \\
& Eggs & $\mathrm{NA}$ \\
& Deli-type salad without meat & $<0.036-840$ \\
All groups & Deli-type salad with meat & $<0.036-3.5 \times 10^{3}$ \\
\hline
\end{tabular}

${ }^{a}$ Results from direct plating method are listed when at least $1 \mathrm{CFU}$ was detected on the plates (i.e., $\geq 10 \mathrm{CFU} / \mathrm{g}$ ); otherwise results from the MPN method are listed. The limits of enumeration were $10 \mathrm{CFU} / \mathrm{g}$ for direct plating and $0.036 \mathrm{MPN} / \mathrm{g}$ for the MPN method. NA, not applicable (no L. monocytogenes isolates were detected).

For seven of the product categories, samples in both types of packaging location were collected. Table 6 shows the total number of samples and the percentage positive for L. monocytogenes in deli-packaged samples and samples prepackaged by manufacturers. For deli-packaged samples, the proportion of positive samples $(95 \% \mathrm{CI})$ ranged from $0.00 \%(0.00,0.42)$ for soft-ripened and semisoft cheese and $0.00 \%(0.00,2.31)$ for eggs to $1.08 \%(0.43,2.21)$ for seafood salad. For prepackaged samples, the proportion of positive samples ranged from $0.00 \%(0.00,0.32)$ for softripened and semisoft cheese to $1.32 \%(0.74,2.17)$ for raw cut vegetables. For individual product categories, there was no significant difference between the two types of packaging location. Overall, the Cochran-Mantel-Haenszel test of general association was not significant, which indicates that across these seven categories the percentage of samples positive for L. monocytogenes was not significantly different between deli-packaged and prepack-

TABLE 5. Detection of L. monocytogenes by food category and state

\begin{tabular}{|c|c|c|c|c|c|c|}
\hline \multirow[b]{2}{*}{ Food group } & \multirow[b]{2}{*}{ Food category } & \multicolumn{4}{|c|}{ L. monocytogenes, positive samples/total samples (\% positive) } & \multirow[b]{2}{*}{$P^{a}$} \\
\hline & & $\mathrm{CA}$ & CT & GA & MD & \\
\hline \multirow[t]{3}{*}{ Seafood } & Smoked seafood & $0 / 196$ & $1 / 183(0.55)$ & 2/179 (1.12) & $0 / 187$ & NS \\
\hline & Seafood salad & $3 / 217(1.38)$ & $1 / 231(0.43)$ & $1 / 262(0.38)$ & $4 / 283(1.41)$ & NS \\
\hline & Fresh crab meat or sushi & $0 / 69$ & $0 / 65$ & $0 / 73$ & $0 / 150$ & NA \\
\hline \multirow[t]{3}{*}{ Produce } & Cut vegetables, raw & $6 / 416(1.44)$ & $0 / 380$ & $2 / 369(0.54)$ & $10 / 524(1.91)$ & 0.0134 \\
\hline & Low-acid cut fruit & $0 / 556$ & $1 / 545(0.18)$ & $7 / 634(1.10)$ & $1 / 673(0.15)$ & 0.0066 \\
\hline & Sprouts & $1 / 667(0.15)$ & $0 / 631$ & $2 / 624(0.32)$ & $0 / 728$ & NS \\
\hline \multirow[t]{4}{*}{ Dairy } & Artisanal cheese & $0 / 640$ & $0 / 534$ & $0 / 637$ & 4/626 (0.64) & 0.0066 \\
\hline & Soft-ripened and semisoft cheese & $0 / 509$ & $0 / 493$ & $0 / 510$ & $0 / 516$ & NA \\
\hline & Cultured milk product & $0 / 61$ & $1 / 109(0.92)$ & $0 / 154$ & $0 / 144$ & NS \\
\hline & Raw milk & $0 / 308$ & $3 / 169(1.78)$ & & & 0.044 \\
\hline \multirow[t]{2}{*}{ Meat } & Deli meat & $1 / 1,283(0.08)$ & $2 / 1,662(0.12)$ & $10 / 1,491(0.67)$ & $2 / 1,481(0.14)$ & 0.0087 \\
\hline & Sausage & $0 / 94$ & $0 / 179$ & $0 / 119$ & $1 / 179(0.56)$ & NS \\
\hline Eggs & Eggs & $0 / 78$ & $0 / 100$ & $0 / 110$ & $0 / 168$ & NA \\
\hline \multirow[t]{3}{*}{ Combination foods } & Deli-type salad without meat & $1 / 553(0.18)$ & 4/627 (0.64) & 4/587 (0.68) & $12 / 690(1.74)$ & 0.027 \\
\hline & Deli-type salad with meat & $0 / 319$ & $0 / 351$ & $2 / 355(0.56)$ & $2 / 390(0.51)$ & NS \\
\hline & Sandwiches & $1 / 528(0.19)$ & $2 / 568(0.35)$ & $2 / 574(0.35)$ & 6/649 (0.92) & NS \\
\hline Total & & $13 / 6,186$ & $12 / 6,658$ & $32 / 6,680$ & $42 / 7,388$ & $0.0001(\mathrm{CMH})^{b}$ \\
\hline
\end{tabular}

${ }^{a}$ Based on a two-factor analysis (Fisher's test); $P \leq 0.05$ indicates a significant difference in the percentage of positive samples between states. NS, not significant; NA, not applicable.

${ }^{b}$ The Cochran-Mantel-Haenszel (CMH) test of general association was used after adjusting for the various food categories, suggesting that the overall association between the percentage of positive samples and the state was significant for L. monocytogenes. 
TABLE 6. Detection of L. monocytogenes by food category and packaging location

\begin{tabular}{|c|c|c|c|}
\hline \multirow[b]{2}{*}{ Food category $^{a}$} & \multicolumn{2}{|c|}{ L. monocytogenes, positive samples/total samples (\% positive $[95 \% \mathrm{CI}]$ ) } & \multirow[b]{2}{*}{$P^{b}$} \\
\hline & Deli packaged & Prepackaged & \\
\hline Seafood salad & $7 / 650(1.08[0.43,2.21])$ & $2 / 343(0.58[0.07,2.09])$ & NS \\
\hline Cut vegetables, raw & $3 / 552(0.54[0.11,1.58])$ & $15 / 1,137(1.32[0.74,2.17])$ & NS \\
\hline Low-acid cut fruit & $7 / 1,259(0.56[0.22,1.14])$ & $2 / 1,149(0.17[0.02,0.63])$ & NS \\
\hline Soft-ripened and semisoft cheese & $0 / 870(0[0.00,0.42])$ & $0 / 1,157(0.00[0.00,0.32])$ & NA \\
\hline Deli-type salads without meat & $15 / 1,515(0.99[0.56,1.63])$ & $6 / 941(0.64[0.23,1.38])$ & NS \\
\hline Eggs & $0 / 158(0[0.00,2.31])$ & $0 / 298(0.00[0.00,1.23])$ & NA \\
\hline Sandwiches & $10 / 2,129(0.47[0.23,0.86])$ & $1 / 184(0.54[0.01,2.99])$ & NS \\
\hline Total & $42 / 7,133$ & $26 / 5,209$ & $\mathrm{NS}(\mathrm{CMH})^{b}$ \\
\hline
\end{tabular}

aged samples (Table 6). Similarly, no significant difference between deli-packaged and prepackaged samples was found for the percentage of samples positive for LLO (data not shown). In previous studies $(8,17)$, a significantly higher percentage of deli-packaged than prepackaged samples of deli meats, seafood salads, and deli-type salads without meats were positive for L. monocytogenes. The lack of any significant differences in the present study between the two types of packaging location might reflect an overall improvement in Listeria control at retail delis targeted in this study or the general lack of statistical power due to the small number of positive samples.

Table 7 shows the percentage of samples positive for $L$. monocytogenes by the type of store. When all 16 categories were considered, no significant difference in the percentage of samples positive for L. monocytogenes was found between samples from national chain stores and those from other store types; however, this finding might reflect a general lack of statistical power due to the small number of positive samples. For L. monocytogenes in raw cut vegetables, a significant difference between store type was found, suggesting that for this food category samples from national chain stores were significantly more likely to be contaminated than were samples from independent regional stores and supplemental stores.

As expected, more samples from all stores types, including for online purchases, tested positive for LLO than for L. monocytogenes. The percentage of samples positive for LLO was significantly higher in samples from nonnational chain stores than in samples from national chain stores when all 16 food categories were considered and for individual categories such as low-acid cut fruit (4.10 versus $1.66 \%)$, soft-ripened and semisoft cheese (1.87 versus $0.45 \%$ ), and deli meat (3.62 versus $1.93 \%$ ) (Table 7). As an indicator for L. monocytogenes, LLO in food samples indicates that food processing or handling conditions may be conducive for survival and growth of L. monocytogenes (48, 52); thus, a higher percentage of LLO-positive samples suggests that corrective actions and greater preventive efforts are needed to control Listeria contamination in these settings.

Comparison of percentage of samples positive for $L$. monocytogenes and pathogen levels between this study and other published surveys of retail RTE foods. Over the past 35 years, many studies have been published on the percentage of samples positive for L. monocytogenes among RTE foods purchased at retail establishments, and many samples of regulated foods have been collected and tested by FSIS and the FDA for the presence of L. monocytogenes. For example, between 1990 and 1999 routine sampling at 1,800 plants inspected by FSIS established an overall prevalence of about $2.8 \%$ among 31,009 meat and poultry products tested (28). In routine and risk-based sampling conducted by FSIS between 2001 and 2015 (50), 831 $(0.49 \%)$ of 170,923 RTE samples were positive for $L$. monocytogenes. Some of those sampling schemes were designed to identify establishments and products of greater risk; therefore, those samples may not have been nationally representative and the $0.49 \%$ prevalence should not be considered an estimate of national prevalence. Between 2014 and 2016, the FDA collected and tested 1,606 samples of raw milk cheese aged 60 days and detected $L$. monocytogenes in 10 samples $(0.62 \%)$, including recovery of the pathogen from domestically produced and imported fresh soft, semisoft, soft-ripened, and hard cheese (analytical sample size equivalent to $50 \mathrm{~g}$ ) (55). In addition to regulatory sampling, a handful of well-designed and wellcontrolled studies have been conducted wherein tens of thousands of foods have been surveyed for the presence and levels of L. monocytogenes in retail foods. For example, Gombas et al. (17) reported that 577 (1.8\%) of 31,705 RTE foods obtained in 2000 and 2001 from retail stores in Maryland and California were positive for L. monocytogenes, and pathogen levels in those positive samples ranged from $<0.3 \mathrm{MPN} / \mathrm{g}$ to $1.5 \times 10^{5} \mathrm{CFU} / \mathrm{g}$. Wallace et al. (61) in 2003 reported that $532(1.6 \%)$ of 32,800 frankfurter packages received from 12 volunteer commercial manufacturers were positive for L. monocytogenes, and pathogen 
TABLE 7. Detection of L. monocytogenes and Listeria-like organisms by food category and store type

\begin{tabular}{|c|c|c|c|c|}
\hline \multirow[b]{2}{*}{ Food group } & \multirow[b]{2}{*}{ Food category } & \multicolumn{2}{|c|}{ Positive samples/total samples (\% positive) } & \multirow[b]{2}{*}{$P^{a}$} \\
\hline & & National chain stores & Other types of stores & \\
\hline \multicolumn{5}{|c|}{ L. monocytogenes } \\
\hline \multirow[t]{3}{*}{ Seafood } & Smoked seafood & $1 / 546(0.18)$ & 2/199 (1.01) & NS \\
\hline & Seafood salad & $4 / 734(0.54)$ & $5 / 259(1.93)$ & NS (0.057) \\
\hline & Fresh crab meat or sushi & $0 / 234$ & $0 / 123$ & NA \\
\hline \multirow[t]{3}{*}{ Produce } & Cut vegetables, raw & $18 / 1,340(1.34)$ & $0 / 349$ & 0.0343 \\
\hline & Low-acid cut fruit & $8 / 1,871(0.43)$ & $1 / 537(0.19)$ & NS \\
\hline & Sprouts & $3 / 1,894(0.16)$ & $0 / 758$ & NS \\
\hline \multirow[t]{4}{*}{ Dairy } & Artisanal cheese & $0 / 371$ & 4/2,066 (0.19) & NS \\
\hline & Soft-ripened and semisoft cheese & $0 / 1,547$ & $0 / 481$ & NA \\
\hline & Cultured milk product & $0 / 331$ & $1 / 137(0.73)$ & NS \\
\hline & Raw milk ${ }^{b}$ & & & NA \\
\hline \multirow[t]{2}{*}{ Meat } & Deli meat & $12 / 4,510(0.27)$ & $3 / 1,407(0.21)$ & NS \\
\hline & Sausage & $1 / 412(0.24)$ & $0 / 159$ & NS \\
\hline Eggs & Eggs & $0 / 362$ & $0 / 94$ & NA \\
\hline \multirow[t]{3}{*}{ Combination foods } & Deli-type salad without meat & $19 / 1,839(1.03)$ & $2 / 618(0.32)$ & NS \\
\hline & Deli-type salad with meat & 4/974 (0.41) & $0 / 441$ & NS \\
\hline & Sandwiches & $8 / 1,733(0.46)$ & $3 / 586(0.51)$ & NS \\
\hline \multirow[t]{2}{*}{ Total } & & $78 / 18,698$ & $21 / 8,214$ & $\mathrm{NS}(\mathrm{CMH})^{c}$ \\
\hline & List & ke organisms & & \\
\hline \multirow[t]{3}{*}{ Seafood } & Smoked seafood & $9 / 546(1.65)$ & $8 / 199(4.02)$ & NS \\
\hline & Seafood salad & $20 / 734(2.72)$ & $12 / 259(4.63)$ & NS \\
\hline & Fresh crab meat or sushi & $10 / 234(4.27)$ & $7 / 123(5.69)$ & NS \\
\hline \multirow[t]{3}{*}{ Produce } & Cut vegetables, raw & $35 / 1,340(2.61)$ & $3 / 349(0.86)$ & NS (0.065) \\
\hline & Low-acid cut fruit & $31 / 1,871(1.66)$ & $22 / 537(4.10)$ & 0.001 \\
\hline & Sprouts & NA & NA & \\
\hline \multirow[t]{4}{*}{ Dairy } & Artisanal cheese & 4/371 (1.08) & $37 / 2,066(1.79)$ & $\mathrm{NS}$ \\
\hline & Soft-ripened and semisoft cheese & $7 / 1,547(0.45)$ & 9/481 (1.87) & 0.005 \\
\hline & Cultured milk product & $3 / 331(0.91)$ & $3 / 137(2.19)$ & NS \\
\hline & Raw milk ${ }^{b}$ & & & NA \\
\hline \multirow[t]{2}{*}{ Meat } & Deli meat & $87 / 4,510(1.93)$ & $51 / 1,407(3.62)$ & $<10^{-4}$ \\
\hline & Sausage & $6 / 412(1.46)$ & $7 / 159(4.40)$ & NS (0.055) \\
\hline Eggs & Eggs & $8 / 362(2.21)$ & 2/94 (2.13) & NA \\
\hline \multirow[t]{3}{*}{ Combination foods } & Deli-type salad without meat & $48 / 1,839(2.61)$ & $23 / 618(3.72)$ & NS \\
\hline & Deli-type salad with meat & $34 / 974(3.49)$ & $13 / 441(2.95)$ & NS \\
\hline & Sandwiches & $42 / 1,733(2.42)$ & $16 / 586(2.73)$ & $\mathrm{NS}$ \\
\hline Total & & $344 / 16,804$ & $213 / 7,456$ & $0.002(\mathrm{CMH})^{c}$ \\
\hline
\end{tabular}

${ }^{a}$ Based on a two-factor analysis (Fisher's test); $P \leq 0.05$ indicates a significant difference. NS, not significant; NA, not applicable.

${ }^{b}$ All raw milk samples were obtained from other types of stores (i.e., not national chains).

${ }^{c}$ The Cochran-Mantel-Haenszel test of general association revealed that in general across all food categories, the percentage of positive samples from national chains stores versus other types of stores was not significantly different for L. monocytogenes but was significantly different for Listeria-like organisms $(P<0.01)$.

levels recovered from a limited number of package rinsates ranged from 71 to $191 \mathrm{MPN}$ per $1-\mathrm{lb}(0.5-\mathrm{kg})$ package. In the NAFSS study, Draughon (8) reported that $55(0.69 \%)$ of 8,015 RTE deli-type meats and poultry products obtained in 2005 and 2006 from retail stores in California, Georgia, Minnesota, and Tennessee were positive for L. monocytogenes. Among these samples, $0.15 \%$ of prepackaged and $1.23 \%$ of deli-sliced products were positive (analytical sample size of $125 \mathrm{~g}$ ), and pathogen levels in positive samples ranged from $<0.08$ to $>100 \mathrm{MPN} / \mathrm{g}$. A survey of 3,063 RTE food samples (e.g., sandwiches of smoked turkey, beef or ham, and smoked salmon) obtained in Florida in 2002 and 2003 (44) revealed an overall $2.97 \%$ samples positive for $L$. monocytogenes (test portion per sample was not reported).

A handful of studies of appreciable scale have also been conducted outside of the United States, including two surveys for L. monocytogenes in RTE foods collected from retail premises in the United Kingdom. In one survey, the percentage of samples positive for $L$. monocytogenes (analytical sample size of $25 \mathrm{~g}$ ) in mixed salads containing meat and seafood ingredients was $4.8 \%$ of the 2,686 samples collected during 2 months in 2005 (30). In the other survey, samples (analytical sample size of $25 \mathrm{~g}$ ) were collected over a 1-year period from 2006 to 2007 (29), and the percentage of samples positive for L. monocytogenes was $7.0 \%$ for 
sandwiches (from 1,012 samples tested), $0.8 \%$ for confectionary products (from 511 samples), and $0.2 \%$ for hard cheese (from 1,240 samples); however, no L. monocytogenes was recovered from butter (878 samples), spreadable cheese (725 samples), or probiotic drinks (368 samples). In Germany, a survey of 2,540 RTE food samples collected between 2010 and 2011 from supermarkets and smaller stores revealed the percentage of samples positive for $L$. monocytogenes was $8.4 \%$ for smoked and gravid fish, $0.7 \%$ for soft and semisoft cheese, and $2.0 \%$ for heat-treated meat products at the end of the product shelf life (4). The European Food Safety Authority (EFSA) (10) reported a survey of 13,088 RTE food samples collected in 27 European countries between January 2010 and January 2012 in which the prevalence of L. monocytogenes in smoked and gravid fish, soft and semisoft cheese, and heattreated meats ranged from 0.43 to $10.4 \%$ (analytical sample size of $25 \mathrm{~g}$ ). These examples of large-scale surveys illustrate continuing efforts both in the United States and internationally to enhance public health by collecting baseline data on L. monocytogenes in RTE foods.

The NFPA 2000 to 2001 survey (17) included eight RTE food categories, five of which were also included in the present survey. The 2005 to 2006 NAFSS survey (8) included one food category that was also sampled in both the NFPA and present surveys. All three surveys included samples collected in FoodNet sites and were similar in scale, scope, study design, and testing methods. In the NFPA survey (17), samples were collected from national chain and independent retail stores in Maryland and California; 577 of 31,705 RTE food samples were positive for L. monocytogenes based on the results of DNA-based assays. Of these 577 L. monocytogenes-positive samples from the NFPA study, 502 (87\%) yielded L. monocytogenes isolates (6), whereas in the present study, L. monocytogenes was isolated from $102(88 \%)$ of the 116 samples positive based on results of the BAX PCR system. The analytical sample size (i.e., the test portion of the sample) has an impact on the percentage of positive samples detected; the larger the test portion, the greater the likelihood of detecting a positive sample. In this study, $25 \mathrm{~g}$ was chosen as the analytical sample size to facilitate comparison with other published surveys, in particular the NFPA study. Gombas et al. (17) reported the percentage of positive samples based on testing a $25 \mathrm{-g}$ food sample with a DNA-based assay specific to L. monocytogenes, i.e., the BAX PCR system for California samples and the Gene-Trak assay for Maryland samples. In the NAFSS survey (8), samples were collected from national chains and small regional and family-owned retail stores; 55 of 8,015 RTE deli meat samples were positive based on results of the Gene-Trak assay with a 125-g analytical sample size.

The percentages of positive samples from comparable food categories obtained with the BAX PCR system used in the present study and the percentages obtained with a DNAbased assay used in the previous two studies were compared using Fisher's exact test. Compared with the results of the 2005 to 2006 NAFSS survey (8), the percentage of positive samples for deli meat sliced or made in the store was significantly lower $(P<0.001), 0.25$ versus $1.23 \%$ (Table
8). This difference, however, might be due in part to a difference in the analytical sample size. The 25-g analytical sample size used in the present study may have lowered the probability of detecting contamination, notably in cases of heterogeneity in the distribution of the pathogen throughout the food matrix, compared with the larger analytical sample size (125 g) used in the NAFSS study. Compared with the NFPA survey a decade ago (analytical sample size of $25 \mathrm{~g}$ ), the percentage of positive samples was significantly lower $(P<0.001)$ in the present study for the five common product categories (Table 8 ): 0.27 versus $4.31 \%$ for smoked seafood, 1.02 versus $4.70 \%$ for seafood salads (excluding tuna salad), 0.049 versus $1.25 \%$ for soft-ripened and semisoft cheeses, 0.25 versus $2.65 \%$ for deli meat made or sliced in the store, and 0.94 versus $2.36 \%$ for deli-type salads without meat (including tuna salad). The decrease in the percentage of positive samples for seafood salad is more similar in magnitude to that for deli salad than that for the other three categories, possibly because of the nature of the product (multiple ingredients) and the handling practices used for RTE salads. These data suggest that L. monocytogenes contamination in some RTE foods has decreased over the past decade probably because of many factors, including industry practices and regulatory policies.

The percentage of positive samples (i.e., the number of positive samples divided by the total number of samples) reported provides an indication of similarities and differences in contamination between this study and reported surveys of a similar large scale. Because of the stratified sampling design and multiple visits to some stores, the percentage of positive samples observed in the present study (e.g., Table 3) and therefore the differences between these results and those obtained in the other studies may not represent differences in the prevalence of $L$. monocytogenes in RTE foods across regions or countries. In another analysis, we used more in-depth modeling to estimate the prevalence of L. monocytogenes, which took into account potential clustering effects originating from the study design.

L. monocytogenes prevalence estimates taking into account clustering effects. In the present study, the sampling plan was not designed to sample all RTE foods available in the United States with equal probability. Samples were collected in only four states, certain foods were intentionally oversampled, and sampling was stratified by state and packaging location (in store or prepackaged by the manufacturer). Multiple products were collected from the same store, and because these products would be exposed to the same retail environment they may have a more similar prevalence of L. monocytogenes than would be expected by chance alone. Generating an ideal sampling design that would exactly represent food consumed or marketed in the United States would have required more indepth knowledge than that available about consumption with regard to food type, such as geographic location, retail channel, brand selection, manufacturing and packaging location, seasonal trends, and potential demographic predictors. Such data and information were not available when this survey was conducted. The sampling design, therefore, was 
TABLE 8. Percentage of RTE food samples positive for $\mathrm{L}$. monocytogenes: present study compared with previous studies ${ }^{a}$

\begin{tabular}{|c|c|c|c|c|c|c|c|}
\hline \multirow[b]{2}{*}{ Food category ${ }^{b}$} & \multicolumn{3}{|c|}{ This study } & \multicolumn{3}{|c|}{ Previous studies } & \multirow[b]{2}{*}{$\begin{array}{c}p \\
\text { (Fisher's test) }\end{array}$} \\
\hline & $\begin{array}{c}\text { No. of } \\
\text { samples }\end{array}$ & $\begin{array}{l}\text { No. BAX } \\
\text { positive }\end{array}$ & $\begin{array}{l}\% \text { positive } \\
(95 \% \mathrm{CI})^{c}\end{array}$ & $\begin{array}{l}\text { No. of } \\
\text { samples }\end{array}$ & $\begin{array}{c}\text { No. BAX or } \\
\text { Gene-Trak positive }\end{array}$ & $\begin{array}{l}\% \text { positive } \\
(95 \% \mathrm{CI})\end{array}$ & \\
\hline Smoked seafood & 745 & 2 & $0.27(0.033,0.97)$ & 2,644 & 114 & $4.31(3.6,5.2)$ & $<0.001$ \\
\hline Seafood salads (excluding tuna salad) & 683 & 7 & $1.02(0.41,2.1)$ & 2,446 & 115 & $4.70(3.9,5.6)$ & $<0.001$ \\
\hline Soft-ripened and semisoft cheeses & 2,028 & 1 & $0.049(0.0012,0.27)$ & 2,970 & 37 & $1.25(0.88,1.7)$ & $<0.001$ \\
\hline Deli meats & 5,917 & 15 & $0.25(0.14,0.42)$ & $\begin{array}{l}2,116 \\
3,984^{d}\end{array}$ & $\begin{array}{l}56 \\
49\end{array}$ & $\begin{array}{l}2.65(2.0,3.4) \\
1.23(0.91,1.6)\end{array}$ & $\begin{array}{l}<0.001 \\
<0.001\end{array}$ \\
\hline $\begin{array}{l}\text { Deli-type salads without meat } \\
\text { (including tuna salad) }\end{array}$ & 2,767 & 26 & $0.94(0.61,1.4)$ & 8,549 & 202 & $2.36(2.1,2.7)$ & $<0.001$ \\
\hline
\end{tabular}

${ }^{a}$ For the present study, samples were collected from 2010 to 2013. For the previous studies, samples were collected in 2000 and 2001 for the NFPA study (17) and 2005 and 2006 for the NAFSS study (8).

${ }^{b}$ Tuna salad was included in the seafood salads category in the present study but in the deli-type salads category in the NFPA study (17). For this comparison, the tuna salad samples in the present study were identified based on information collected from the product labels (the ingredients list) and placed into the deli-type salads without meat category for the analysis.

${ }^{c}$ The percentage of samples positive for L. monocytogenes was based on detection by the BAX PCR system (this study and the NFPA study (17)) or the Gene-Trak assay (the NAFSS study (8)). The NFPA study included all five food categories, and the NAFSS study included only one food category (deli meats). The confidence interval (CI) was the Clopper and Pearson 95\% CI based on a published methodology (7).

${ }^{d}$ Deli meat samples were made in the store only in the present study; therefore, only the made-in-store samples from the previous studies $(8,17)$ were included in the comparison.

developed using a somewhat pragmatic approach based on stratification by predictors anticipated to have the greatest impact and collection of multiple samples from multiple food categories from the same store for efficiency. With this sampling design, to estimate the L. monocytogenes prevalence and compare it with the prevalence found in other studies, the data analysis must consider both the stratification and the potential store clustering effect $(21,36,42)$. Generalized linear mixed models were used to determine prevalence estimates with consideration of clustering effects in three ways: (i) random effect not considered (i.e., as a control in the analysis, no random effect or including state as a fixed effect), (ii) random effect considered with regard to states, and (iii) random effect considered with regard to stores within states. For this analysis, the prevalence was calculated separately for product prepackaged by the manufacturer versus that made or sliced in the store. To calculate the prevalence for the combined samples from both packaging locations would require data on the proportion of product sold per location (prepackaged versus deli packaged); however, such information was not available at the time of this study.

L. monocytogenes prevalence was estimated for 13 of the 16 product categories; three food categories (soft-ripened and semisoft cheese, eggs, and fresh crab meat or sushi) were not included in the models because no L. monocytogenes cells were isolated from these foods. For the 13 food categories from which a viable isolate of $L$. monocytogenes was recovered, all the samples in each food category were divided into two subcategories as appropriate: prepackaged (samples prepackaged in a manufacturing plant) and deli packaged (samples made or sliced at the retail store). A total of 17 subcategories were identified among the 13 product categories (Table 9): 9 of the 13 categories included samples from only one subcategory (either prepackaged or deli packaged), but for 4 of the 13 categories, samples were collected from both subcategories (prepackaged and deli packaged). Among the nine food categories, only prepackaged samples were available for smoked seafood, sprouts, artisanal cheese, cultured milk product, and raw milk; only deli-packaged samples were available for deli meat, sausage, deli salad with meat, and sandwiches. For the four product categories with samples from both subcategories (i.e., seafood salad, deli-type salad without meat, raw cut vegetables, and low-acid cut fruit), samples were separated by subcategories for the analysis. A small number of samples did not fit the subcategorization scheme and therefore were not considered in this analysis. For example, only 20 of the smoked seafood samples collected were made in the retail store; therefore, those samples were excluded from this analysis because the small number of samples would lead to an unbalanced model and possibly to an inaccurate prevalence estimation. Similarly, one artisanal cheese sample (sliced in the store), four sausage samples (prepackaged), and 32 cultured milk product samples (e.g., dips made in the store) were excluded because of these small sample numbers. Samples with no identified store code or manufacturing location were also excluded. Overall, the subcategorization approach resulted in a total of 24,359 samples with a specified packaging location for the 17 subcategories, for which the number of samples positive for L. monocytogenes ranged from 1 to 15 , and the associated number of stores from which positive samples were collected ranged from 1 to 12 (Table 9).

L. monocytogenes prevalence was estimated for the 17 subcategories according to the packaging location (Table 9). When the model accounted for state as a random effect with store nested within state, the prevalence $(95 \% \mathrm{CI})$ differed among the product subcategories: (i) seafood, $0.30 \%(0.10$, $0.97)$ to $0.84 \%(0.39,1.81)$; (ii) produce, $0.11 \%(0.03,0.34)$ 
TABLE 9. Prevalence of $\mathrm{L}$. monocytogenes with consideration of clustering effects ${ }^{a}$

\begin{tabular}{|c|c|c|c|c|c|c|}
\hline Food group & Food category & $\begin{array}{l}\text { Random effect } \\
\text { not considered }\end{array}$ & $\begin{array}{l}\text { Random effect, } \\
\text { state }\end{array}$ & $\begin{array}{l}\text { Random effect, } \\
\text { store (state) }\end{array}$ & $\begin{array}{l}\text { No. of positive } \\
\text { samples }\end{array}$ & $\begin{array}{c}\text { No. of stores } \\
\text { with positive } \\
\text { samples }\end{array}$ \\
\hline \multirow[t]{4}{*}{ Seafood } & Smoked seafood: PP & $0.37(0.12,1.15)$ & $0.38(0.11,1.32)$ & $0.30(0.10,0.97)$ & 3 & 2 \\
\hline & Seafood salad: DP & $0.92(0.43,1.94)$ & $0.96(0.39,2.34)$ & $0.84(0.39,1.81)$ & 7 & 5 \\
\hline & Seafood salad: PP & $0.49(0.12,1.95)$ & $0.51(0.12,2.22)$ & $0.46(0.11,1.86)$ & 2 & 2 \\
\hline & $\begin{array}{l}\text { Fresh crab meat } \\
\quad \text { or sushi }\end{array}$ & NA & & & 0 & 0 \\
\hline \multirow[t]{5}{*}{ Produce } & $\begin{array}{l}\text { Cut vegetables, } \\
\text { raw: DP }\end{array}$ & $0.46(0.15,1.44)$ & $0.48(0.14,1.66)$ & $0.44(0.14,1.40)$ & 3 & 3 \\
\hline & $\begin{array}{l}\text { Cut vegetables, } \\
\text { raw: PP }\end{array}$ & $1.14(0.68,1.91)$ & $1.18(0.57,2.42)$ & $1.01(0.58,1.74)$ & 15 & 11 \\
\hline & $\begin{array}{l}\text { Low-acid cut } \\
\text { fruit: DP }\end{array}$ & $0.46(0.22,0.97)$ & $0.48(0.19,1.18)$ & $0.34(0.15,0.76)$ & 7 & 5 \\
\hline & $\begin{array}{l}\text { Low-acid cut } \\
\text { fruit: PP }\end{array}$ & $0.15(0.04,0.62)$ & $0.16(0.04,0.70)$ & $0.12(0.03,0.49)$ & 2 & 2 \\
\hline & Sprouts: PP & $0.10(0.03,0.31)$ & $0.10(0.03,0.36)$ & $0.11(0.03,0.34)$ & 3 & 2 \\
\hline \multirow[t]{4}{*}{ Dairy } & Artisanal cheese: PP & $0.14(0.05,0.38)$ & $0.15(0.05,0.45)$ & $0.13(0.05,0.37)$ & 4 & 3 \\
\hline & $\begin{array}{l}\text { Soft-ripened and } \\
\text { semisoft cheese }\end{array}$ & NA & & & 0 & 0 \\
\hline & $\begin{array}{r}\text { Cultured milk } \\
\text { product: PP }\end{array}$ & $0.18(0.03,1.28)$ & $0.19(0.03,1.44)$ & $0.16(0.02,1.16)$ & 1 & 1 \\
\hline & Raw milk: PP & $1.04(0.33,3.26)$ & $0.96(0.27,3.32)$ & $0.47(0.13,1.67)$ & 3 & 2 \\
\hline \multirow[t]{2}{*}{ Meat } & Deli meat: DP & $0.23(0.13,0.38)$ & $0.23(0.11,0.48)$ & $0.19(0.11,0.33)$ & 15 & 9 \\
\hline & Sausage: DP & $0.15(0.02,1.08)$ & $0.16(0.02,1.19)$ & $0.13(0.02,0.93)$ & 1 & 1 \\
\hline Eggs & Eggs & NA & & & 0 & 0 \\
\hline \multirow[t]{4}{*}{ Combination foods } & $\begin{array}{l}\text { Deli-type salad } \\
\text { without meat: DP }\end{array}$ & $0.87(0.52,1.46)$ & $0.90(0.44,1.85)$ & $0.72(0.42,1.23)$ & 15 & 12 \\
\hline & $\begin{array}{l}\text { Deli-type salad } \\
\text { without meat: PP }\end{array}$ & $0.54(0.24,1.22)$ & $0.56(0.22,1.46)$ & $0.50(0.22,1.13)$ & 6 & 5 \\
\hline & $\begin{array}{l}\text { Deli-type salad } \\
\text { with meat: DP }\end{array}$ & $0.26(0.10,0.70)$ & $0.27(0.09,0.82)$ & $0.22(0.08,0.60)$ & 4 & 3 \\
\hline & Sandwiches: DP & $0.41(0.22,0.76)$ & $0.42(0.19,0.94)$ & $0.36(0.19,0.68)$ & 10 & 10 \\
\hline
\end{tabular}

${ }^{a}$ Prevalence is given as a percentage $(95 \% \mathrm{CI})$ and was calculated for 13 of the 16 product categories from which L. monocytogenes was isolated, separated by packaging location: PP, prepackaged by manufacturer; DP, deli packaged (made or sliced in the retail store). Seventeen subcategories were included in this analysis because not all food categories included both PP and DP samples. NA, not applicable.

to $1.01 \%(0.58,1.74)$; (iii) dairy, $0.13 \%(0.05,0.37)$ to $0.47 \%(0.13,1.67)$; (iv) meat, $0.13 \%(0.02,0.93)$ to $0.19 \%$ $(0.11,0.33)$; and (v) combination foods, $0.22 \%(0.08,0.60)$ to $0.72 \%(0.42,1.23)$. Table 9 also shows that the prevalence estimates change slightly with the model used. Among these three sets of estimates, the prevalence estimates based on the analysis that considered whether a store was visited multiple times and the state location of the store as a variable in the model, i.e., random effect, store (state), most closely represent the true prevalence of $L$. monocytogenes in the products in the United States, based on consideration of the sampling design. All elements being equal, multiple positive samples found in the same store would effectively lead to a lower value for the prevalence estimate (with consideration of random effect, store [state]) than the positive rate (the number of positive samples divided by the total number of samples).

In this study, the prevalence among the RTE food categories (Table 9) was significantly different $(P=0.001)$, regardless of whether the store effect, i.e., random effect, store (state), was considered. Within a given food category, packaging location (i.e., prepackaged versus deli packaged) was not significant for any category for which the comparison could be done, i.e., for seafood salad, raw cut vegetables, low-acid cut fruit, and deli-type salad without meat. This lack of a significant effect is partly due to the limited statistical power of this analysis associated with the very small number of positive samples (Table 9).

Although the number of positive samples per food category was generally low, the large number of total samples tested in this study made it possible to determine whether differences in prevalence existed among the products. For example, when a comprehensive comparison was made between one specific subcategory (e.g., delipackaged seafood salad) and the rest of the subcategories, the prevalence was significantly different for deli-packaged seafood salad versus both deli packaged and prepackaged low-acid cut fruit, prepackaged sprouts, deli-packaged deli meat, and deli-packaged deli-type salad with meat. Where significant differences were found (see specific description of the differences among the subcategories in Supplemental Table S5 footnote), the results indicate whether the 


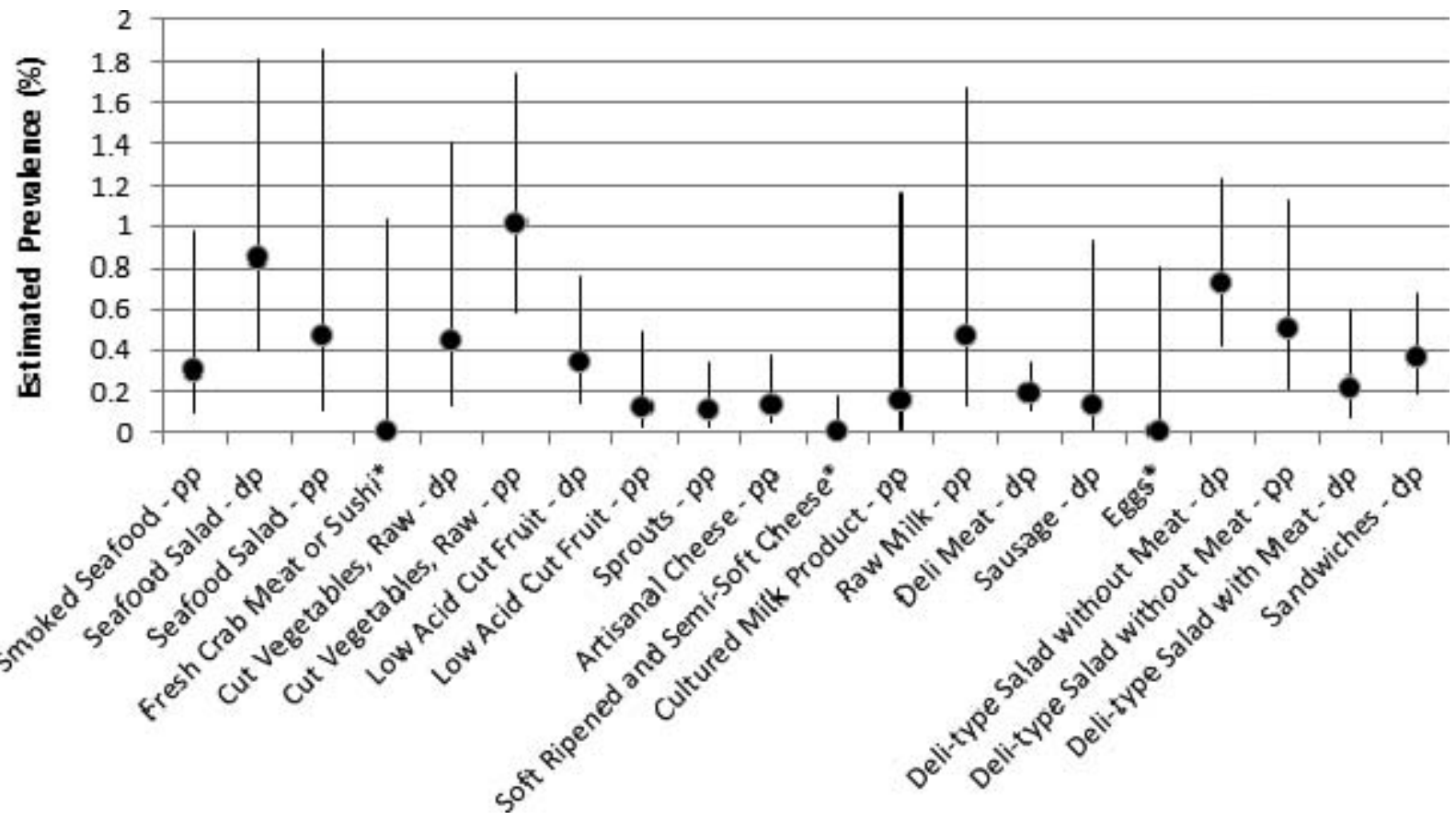

FIGURE 1. Prevalence of L. monocytogenes based on analysis with consideration of clustering effects. Close circles represent the mean; solid lines represent the $95 \%$ confidence interval. Prevalence was not estimated for three food categories for which no L. monocytogenespositive samples were confirmed: fresh crab meat or sushi, soft-ripened and semisoft cheese, and eggs; the percentage of positive samples for these categories (clustering effects not considered) is shown as a reference. pp, prepackaged; dp, deli packaged.

prevalence was significantly higher or lower in one subcategory than another for the subcategories in the comprehensive comparison (Table 9), which is displayed in Figure 1.

In the 2010 to 2012 baseline survey in the European Union (EU) reported by EFSA (10) in which samples were collected from both supermarkets and small shops and a 25g sample was analyzed using an approved International Organization for Standardization method (24), the prevalence $(95 \% \mathrm{CI})$ of L. monocytogenes in the EU samples was $10.4 \%$ (9.1 to $11.7 \%$ ) and $10.3 \%$ (9.1 to $11.6 \%)$ for packaged smoked or gravid fish (from total of 3,053 samples) at the time of sampling and at the end of the shelf life, respectively. At the end of shelf life, the prevalence was $2.07 \%$ (1.63 to $2.64 \%$ ) for prepackaged heat-treated meat products (total of 3,530 samples) and $0.47 \%$ (0.29 to $0.77 \%$ ) for soft and semisoft cheese (total of 3,452 samples). Given the similarities in design, scope, and detection limits between the EFSA and the present study, some comparisons can be made. L. monocytogenes prevalence in smoked fish was considerably higher in the EU (10.4\%) than in the United States $(0.30 \%)$ samples. The prevalence of $L$. monocytogenes in packaged RTE meat products also was higher in the EU data set $(2.07 \%)$ than in the U.S. delipackaged meat samples $(0.19 \%)$. Science-based policies and guidance by regulatory agencies and attendant ongoing advances related to product formulation, processing, and/or packaging made since the mid-2000s by manufacturers of RTE products, particularly those identified as higher volume and higher risk, have presumably lowered the risk of listeriosis attributed to some of the foods tested herein.
Limitations of this study. The findings from this study reflect $L$. monocytogenes contamination in the selected RTE foods at one point in time, and the estimated proportion of positive samples and the prevalence are conditioned upon the study design, analytical sample size (25 g), and testing methods. Although the methods used for screening, isolation, and confirmation were scientifically sound, reproducible, and validated, the recovery of L. monocytogenes can be complicated by the presence of background microflora that may be present in the selected RTE foods (the 16 RTE food categories may not have had a lethality step or may have been exposed after the lethality step to the processing and retail environments). The recovery of LLO from enrichment cultures following screening steps via the BAX PCR system or OXA culture may negatively impact the ability to recover pathogenic species or serotypes of Listeria. Keys et al. (25) reported that L. innocua appreciably outcompeted $L$. monocytogenes serotype 4 b by 0.2 to $2.4 \log \mathrm{CFU} / \mathrm{mL}$ in enrichment culture after incubation at $30^{\circ} \mathrm{C}$ for $48 \mathrm{~h}$. Under such conditions, the initial presence of higher levels of $L$. innocua than $L$. monocytogenes could make it more difficult to recover the latter from food products and, in turn, could lead to an erroneously elevated number of false-negative results for $L$. monocytogenes. In this study, a higher percentage of samples were positive for LLO than for L. monocytogenes, and it is uncertain the degree to which this difference might have resulted in false-negative results for some of the samples that tested positive for LLO. Thus, we reported results for LLO, presumptive-positive L. monocytogenes based on the BAX PCR assay, and confirmed positive $L$. monocytogenes based on culture isolation to shed some light 
on the recovery and potential false-negative issue. The correlation between the percentage of positive samples confirmed by L. monocytogenes isolation versus that determined by the BAX PCR system is shown in Supplemental Figure S2, where for 10 of the 16 food categories, the number of samples confirmed by retention or confirmation of viable L. monocytogenes cells was lower than that by the BAX assay (17 of the 116 BAX-positive samples did not yield an L. monocytogenes isolate). The fact that $17(15 \%)$ of 116 samples that tested BAX positive did not yield an L. monocytogenes isolate might also be due to interference from background microflora; the information is insufficient to determine the rate of false-negative results. However, a sample that tested negative for LLO is unlikely to be falsely negative for L. monocytogenes.

In contrast to previous studies in which the percentage of samples positive for L. monocytogenes was higher in samples prepared and packaged at the retail store than in those prepackaged at the manufacturing plant for deli meats $(8,17)$ and for deli salads and seafood salads $(17)$, in the present study no significant difference between delipackaged and prepackaged samples were found for seafood salads, raw cut vegetables, low-acid cut fruits, soft-ripened and semisoft cheese, deli-type salads without meat, eggs, and sandwiches. No significant differences in L. monocytogenes recovery rates were also found between samples from large national chain stores and independent stores, with the exception of the raw cut vegetables category. The absence of differences might be due in part to the small number of samples confirmed positive for L. monocytogenes.

This interagency L. monocytogenes market basket survey is the most comprehensive survey of L. monocytogenes in retail RTE foods in the United States conducted in the past decade. The data presented here are being used to assess changes in L. monocytogenes prevalence in specific categories of RTE foods. Overall, findings from this study establish that the occurrence of L. monocytogenes in the targeted RTE foods has decreased and that the prevalence is lower than that estimated for samples collected over a decade ago. This trend has spanned the same time period when new regulations and regulatory guidance and new industry guidance by various sectors were implemented. The reduction in contamination in the tested product categories may in part reflect regulatory and industry efforts over the last decade such as improved sanitary conditions and product formulation to control L. monocytogenes in RTE foods. These data demonstrate the utility of periodic research to quantify the occurrence, populations, persistence, and types of pathogens such as L. monocytogenes in RTE foods and to evaluate the potential likelihood of cross-contamination in or on foods within a deli case, at salad and olive bars, and at food kiosks in grocery stores.

\section{ACKNOWLEDGMENTS}

This study was a multiyear collaborative project among the USDA ARS, the FDA, the USDA FSIS, and several universities, including Drexel University. The project was funded by the ARS, FDA, and FSIS through interagency agreements with the ARS. This work was also was supported in part by appointments to the Research Participation Program at the FDA
Center for Food Safety and Applied Nutrition administered by the Oak Ridge Institute for Science and Education through an interagency agreement between the U.S. Department of Energy and the FDA. Mention of trade names or commercial products in this publication is solely for the purpose of providing specific information and does not imply recommendation or endorsement by the USDA or the FDA.

\section{SUPPLEMENTAL MATERIAL}

Supplemental material associated with this article can be found online at: https://doi.org/10.4315/0362-028X.JFP-16-420.s1.

\section{REFERENCES}

1. American Cheese Society. 2012. Cheese glossary: what is artisan or artisanal cheese?; Online marketplace, find a cheese company, type of business: cheesemaker. Available at: http://www.cheesesociety.org/iheart-cheese/cheese-glossary/ and http://www.cheesesociety.org/iheart-cheese/marketplace/. Accessed 5 April 2012.

2. AOAC International. 2005. Evaluation of BAX ${ }^{\circledR}$ automated system for the detection of Listeria monocytogenes in foods. AOAC official method 2003.12, chap. 17.10.10, p. 222-225. In W. Horwitz (ed.), Official methods of analysis of AOAC International, 18th ed. AOAC International, Gaithersburg, MD.

3. Batz, M. B., S. Hoffmann, and J. G. Morris, Jr. 2012. Ranking the disease burden of 14 pathogens in food sources in the United States using attribution data from outbreak investigations and expert elicitation. J. Food Prot. 75:1278-1291.

4. Bundesinstitut für Risikobewertung. 2013. Baseline study on the prevalence of Listeria monocytogenes in specific ready-to-eat foods. Updated BfR opinion no. 011/2013. Available at: http://www.bfr. bund.de/cm/349/baseline-study-on-the-prevalence-of-listeriamonocytogenes-in-specific-ready-to-eat-foods.pdf. Accessed 22 October 2015.

5. Chen, Y., S. Dennis, K. Hoelzer, J. Luchansky, L. Papadakis, A. Porto-Fett, R. Pouillot, and B. Shoyer. 2013. Survey of Listeria monocytogenes in ready-to-eat foods in the United States (FDA regulated products_-phase I): assessing potential changes in a decade, p. 210-211. In F. Tenenhaus-Aziza and M. Elouze (ed.), Predictive microbiology in food: today's tools to meet stakeholders' expectations. Proceedings of the International Conference on Predictive Modelling in Food (ICPMF8), Paris, France, 16 to 20 September 2013.

6. Chen, Y., W. H. Ross, V. N. Scott, and D. E. Gombas. 2003. Listeria monocytogenes: low levels equal low risk. J. Food Prot. 66:570-577.

7. Clopper, C. J., and E. S. Pearson. 1934. The use of confidence or fiducial limits illustrated in the case of the binomial. Biometrika 26:404-413.

8. Draughon, A. F. 2009. Listeria monocytogenes: prevalence and levels in deli-meat at retail - the NAFSS study. USDA-FSIS meeting on the interagency retail Listeria monocytogenes risk assessment. Available at: http://www.fsis.usda.gov/wps/wcm/connect/d29d79a0-0cea-4504a73f-1ecb38bfee9a/Lm_Draughon_062309.pdf?MOD=AJPERES. Accessed 16 March 2016.

9. Endrikat, S., D. Gallagher, R. Pouillot, H. Hicks Quesenberry, D. Labarre, C. M. Schroeder, and J. Kause. 2010. A comparative risk assessment for Listeria monocytogenes in prepackaged versus retailsliced deli meat. J. Food Prot. 73:612-619.

10. European Food Safety Authority. 2013. Analysis of the baseline survey on the prevalence of Listeria monocytogenes in certain readyto-eat foods in the EU, 2010-2011. Part A. Listeria monocytogenes prevalence estimates. EFSA J. 11:3241. doi:10.2903/j.efsa.2013.3241.

11. Farber, J. M., and P. I. Peterkin. 1991. Listeria monocytogenes, a food-borne pathogen. Microbiol. Rev. 55:476-511.

12. Ferreira, V., M. Wiedmann, P. Teixeira, and M. J. Stasiewicz. 2014. Listeria monocytogenes persistence in food-associated environments: epidemiology, strain characteristics, and implications for public health. J. Food Prot. 77:150-170.

13. Food and Agriculture Organization of the United Nations, World Health Organization. 2004. Risk assessment of Listeria monocyto- 
genes in ready to eat foods-technical report. Available at: http:// www.fao.org/docrep/010/y5394e/y5394e00.htm. Accessed 22 October 2015 .

14. Fretz, R., J. Pichler, U. Sagel, P. Much, W. Ruppitsch, A. Pietzka, A. Stoger, S. Huhulescu, S. Heuberger, G. Appl, D. Werber, K. Stark, R. Prager, A. Flieger, R. Karpiskova, G. Pfaff, and F. Allerberger. 2010. Update: multinational listeriosis outbreak due to 'Quargel', a sour milk curd cheese, caused by two different L. monocytogenes serotype 1/2a strains, 2009-2010. Euro Surveill. 15(16):pii=19543.

15. Fretz, R., U. Sagel, W. Ruppitsch, A. T. Pietzka, A. Stoger, S. Huhulescu, S. Heuberger, J. Pichler, P. Much, G. Pfaff, K. Stark, R. Prager, A. Flieger, O. Feenstra, and F. Allerberger. 2010. Listeriosis outbreak caused by acid curd cheese 'Quargel', Austria and Germany 2009. Euro Surveill. 15(5):pii=19477.

16. Gall, K., V. N. Scott, R. Collette, M. Jahncke, D. Hicks, and M. Wiedmann. 2004. Implementing targeted good manufacturing practices to minimize Listeria contamination in smoked seafood products. Food Prot. Trends 24:3302-3315.

17. Gombas, D. E., Y. Chen, R. S. Clavero, and V. N. Scott. 2003. Survey of Listeria monocytogenes in ready-to-eat foods. J. Food Prot. 66:559-569.

18. Gram, L. 2001. Potential hazards in cold-smoked fish: Listeria monocytogenes, chap. II. In Processing parameters needed to control pathogens in cold-smoked fish. Institute of Food Technologists (IFT) Report for FDA/CFSAN. J. Food Sci. 66:S1072-S1081.

19. Grocery Manufacturers Association (GMA) Sanitary Design Workgroup. 2013. Sanitation lexicon: collections of terms, definitions and useful resources associated with sanitation and sanitary principles. Available at: http://www.gmaonline.org/file-manager/About/ Sanitation_Lexicon-GMA_Sanitary_Design_Workgroup-2013.pdf. Accessed 17 November 2015.

20. Hoelzer, K., Y. Chen, S. Dennis, P. Evans, R. Pouillot, B. J. Silk, and I. Walls. 2013. New data, strategies, and insights for Listeria monocytogenes dose-response models: summary of an interagency workshop, 2011. Risk Anal. 33:1568-1581.

21. Hoelzer, K., B. Sauders, M. Sanchez, P. Olsen, M. Pickett, K. Mangione, D. Rice, J. Corby, S. Stich, E. Fortes, S. Roof, Y. Grohn, M. Wiedmann, and H. Oliver. 2011. Prevalence, distribution, and diversity of Listeria monocytogenes in retail environments, focusing on small establishments and establishments with a history of failed inspections. J. Food Prot. 74:1083-1095.

22. Hoffmann, S., B. Maculloch, and M. Batz. 2015. Economic burden of major foodborne illnesses acquired in the United States. Economic information bulletin 140. U.S. Department of Agriculture, Economic Research Service, Washington, DC.

23. Innovation Center for U.S. Dairy. 2015. Control of Listeria monocytogenes: guidance for the U.S. dairy industry. Available at: http://www.idfa.org/docs/default-source/resource-library/guidancefor-the-us-dairy-industry-10-19-15.pdf. Accessed 16 March 2016.

24. International Organization for Standardization. 2004. Microbiology of food and animal feeding stuffs-horizontal method for the detection and enumeration of Listeria monocytogenes. Part 1. Detection method. EN ISO 11290-1:1996/A1:2004. International Organization for Standardization, Geneva.

25. Keys, A. L., R. C. Dailey, A. D. Hitchins, and R. D. Smiley. 2013. Post enrichment population differentials using buffered Listeria enrichment broth: implications of the presence of Listeria innocua on Listeria monocytogenes in food test samples. J. Food Prot. 76:1854-1862.

26. Kramer, D. E., and L. Brown (ed.). 2008. International Smoked Seafood Conference proceedings. Alaska Sea Grant College Program, University of Alaska, Fairbanks.

27. Lado, B. H., and A. E. Yousef. 2007. Characteristics of Listeria monocytogenes important to food processors, p. 157-213. In E. T. Ryser and E. H. Marth (ed.), Listeria, listeriosis, and food safety. CRC Press, Boca Raton, FL.

28. Levine, P., B. Rose, S. Green, G. Ransom, and W. Hill. 2001. Pathogen testing of ready-to-eat meat and poultry products collected at federally inspected establishments in the United States, 1990 to 1999. J. Food Prot. 64:1188-1193.

29. Little, C. L., S. K. Sagoo, I. A. Gillespie, K. Grant, and J. McLauchlin. 2009. Prevalence and level of Listeria monocytogenes and other Listeria species in selected retail ready-to-eat foods in the United Kingdom. J. Food Prot. 72:1869-1877.

30. Little, C. L., F. C. Taylor, S. K. Sagoo, I. A. Gillespie, K. Grant, and J. McLauchlin. 2007. Prevalence and level of Listeria monocytogenes and other Listeria species in retail pre-packaged mixed vegetable salads in the UK. Food Microbiol. 24:711-717.

31. Luchansky, J. B., A. C. S. Porto-Fett, S. Dennis, Y. Chen, R. Pouillot, K. Hoelzer, L. Gathercole, L. Papadakis, L. Williams, B. A. Shoyer, J. Lee, J. A. Lindsay, J. Kause, E. Mbandi, D. Eblen, W. Shaw, D. Gallagher, V. Cook, N. Bauer, R. Johnson, J. King, M. Murphy, J. Nasella, H. E. Starks, S. Khokhar, C. A. Spurlino, T. Nguyen, K. Berry, A. Kanjanakorn, S. Wadsworth, E. G. Baker, C. Harvey, C. Reed, K. Martino, and L. A. Benjamin. 2012. Prevalence and levels of Listeria monocytogenes (Lm) in ready-to-eat foods (RTE) at retail, p. 217, P3-145. Abstr. Annu. Meet. IAFP 2012. International Association for Food Protection, Des Moines, IA.

32. Meldrum, R. J., P. W. Ellis, P. T. Mannion, D. Halstead, and J. Garside, on behalf of the Welsh Food Microbiological Forum. 2010. Prevalence of Listeria monocytogenes in ready-to-eat foods sampled from the point of sale in Wales, United Kingdom. J. Food Prot. 73:1515-1518.

33. Mellefont, L. A., and T. Ross. 2007. Effect of potassium lactate and a potassium lactate-sodium diacetate blend on Listeria monocytogenes growth in modified atmosphere packaged sliced ham. J. Food Prot. 70:2297-2305.

34. Nelson, K. E., D. E. Fouts, E. F. Mongodin, J. Ravel, R. T. DeBoy, J. F. Kolonay, D. A. Rasko, S. V. Angiuoli, S. R. Gill, I. T. Paulsen, J. Peterson, O. White, W. C. Nelson, W. Nierman, M. J. Beanan, L. M. Brinkac, S. C. Daugherty, R. J. Dodson, A. S. Durkin, R. Madupu, D. H. Haft, J. Selengut, S. Van Aken, H. Khouri, N. Fedorova, H. Forberger, B. Tran, S. Kathariou, L. D. Wonderling, G. A. Uhlich, D. O. Bayles, J. B. Luchansky, and C. M. Fraser. 2004. Whole genome comparisons of serotype $4 \mathrm{~b}$ and $1 / 2 \mathrm{a}$ strains of the food-borne pathogen Listeria monocytogenes reveal new insights into the core genome components of this species. Nucleic Acids Res. 32:23862395.

35. North American Meat Institute Foundation. 2015. Listeria monocytogenes. Available at: http://www.namif.org/fact-sheets/listeriamonocytogenes. Accessed 16 November 2015.

36. Pendergast, J. F., S. J. Gange, and M. J. Lindstrom. 2005. Correlated binary data. In P. Armitage and T. Colton (ed.), Encyclopedia of biostatistics, 2nd ed. John Wiley and Sons, Hoboken, NJ. doi:10. 1002/0470011815.b2a10018.

37. Porto-Fett, A. C. S., J. E. Call, P. M. Muriana, T. A. Freier, and J. B. Luchansky. 2010. Listeria monocytogenes, p. 95-107. In V. K. Juneja and J. N. Sofos (ed.), Pathogens and toxins in foods: challenges and interventions. American Society for Microbiology, Washington, DC.

38. Pouillot, R., D. Gallagher, J. Tang, K. Hoelzer, J. Kause, and S. B. Dennis. 2015. Listeria monocytogenes in retail delicatessens: an interagency risk assessment-model and baseline results. J. Food Prot. 78:134-145.

39. Ryser, E. T., and R. L. Buchanan. 2013. Listeria monocytogenes, p. 503-545. In M. P. Doyle and R. L. Buchanan (ed.), Food microbiology: fundamentals and frontiers. American Society for Microbiology, Washington, DC.

40. Ryser, E. T., and E. H. Marth. 1999. Listeria, listeriosis, and food safety. Marcel Dekker, New York.

41. Scallan, E., R. Hoekstra, F. Angulo, R. Tauxe, M. Widdowson, S. Roy, J. Jones, and P. Griffin. 2011. Foodborne illness acquired in the United States-major pathogens. Emerg. Infect. Dis. 17:7-15.

42. Schukken, Y. H., Y. T. Grohn, B. McDermott, and J. J. McDermott. 2003. Analysis of correlated discrete observations: background, examples and solutions. Prev. Vet. Med. 59:223-240.

43. Scott, V. N., K. M. J. Swanson, T. A. Freier, W. P. Pruett, Jr., W. H. Sveum, P. A. Hall, L. A. Smoot, and D. G. Brown. 2005. Guidelines 
for conducting Listeria monocytogenes challenge testing of foods. Food Prot. Trends 25:818-825.

44. Shen, Y., Y. Liu, Y. Zhang, J. Cripe, W. Conway, J. Meng, G. Hall, and A. A. Bhagwat. 2006. Isolation and characterization of Listeria monocytogenes isolates from ready-to-eat foods in Florida. Appl. Environ. Microbiol. 72:5073-5076.

45. U.S. Department of Agriculture, Food Safety and Inspection Service. 2003. Control of Listeria monocytogenes in ready-to-eat meat and poultry products; interim final rule; 9 CFR part 430 . Available at: https://www.gpo.gov/fdsys/pkg/FR-2003-06-06/pdf/03-14173.pdf. Accessed 7 December 2016.

46. U.S. Department of Agriculture, Food Safety and Inspection Service. 2003. FSIS risk assessment for Listeria monocytogenes in deli meats. Available at: http://www.fsis.usda.gov/wps/wcm/connect/b5027918ee69-475e-acc9-a07c642f13b6/Lm_Deli_Risk_Assess_Final_2003. pdf?MOD=AJPERES. Accessed 22 October 2015.

47. U.S. Department of Agriculture, Food Safety and Inspection Service. 2010. FSIS comparative risk assessment for Listeria monocytogenes in ready-to-eat meat and poultry deli meats. Available at: http://www. fsis.usda.gov/wps/wcm/connect/c2ac97d0-399e-4c4a-a2bcd338c2e201b3/Comparative_RA_Lm_Report_May2010.pdf? MOD=AJPERES. Accessed 22 October 2015.

48. U.S. Department of Agriculture, Food Safety and Inspection Service. 2012. FSIS compliance guideline: controlling Listeria monocytogenes in post-lethality exposed ready-to-eat meat and poultry products. Available at: http://www.fsis.usda.gov/PDF/Controlling_LM_RTE_ guideline_0912.pdf. Accessed 22 October 2015.

49. U.S. Department of Agriculture, Food Safety and Inspection Service. 2013. Isolation and identification of Listeria monocytogenes from red meat, poultry and egg products, and environmental samples, chap. 8. In Microbiological laboratory guide. Available at: http://www.fsis. usda.gov/wps/wcm/connect/1710bee 8-76b9-4e6c-92fcfdc290dbfa92/MLG-8.pdf?MOD=AJPERES. Accessed 22 October 2015.

50. U.S. Department of Agriculture, Food Safety and Inspection Service. 2016. FSIS microbiological testing program for ready to eat (RTE) meat and poultry products, 1990-2015. Available at: http://www.fsis. usda.gov/wps/portal/fsis/topics/data-collection-and-reports/ microbiology/testing-program-for-rte-meat-and-poultry-products. Accessed 6 September 2016.

51. U.S. Department of Agriculture, Food Safety and Inspection Service and U.S. Food and Drug Administration. 2011. Update of the 2003 interagency quantitative assessment of the relative risk to public health from foodborne Listeria monocytogenes among selected categories of ready-to-eat foods; request for comments, scientific data and information. Fed. Regist. 76:19311-19313.

52. U.S. Food and Drug Administration. 2008. Guidance for industry: control of Listeria monocytogenes in refrigerated or frozen ready-toeat foods; draft guidance. Available at: http://www.fda.gov/Food/ GuidanceRegulation/GuidanceDocumentsRegulatoryInformation/ FoodProcessingHACCP/ucm073110.htm. Accessed 22 October 2015.
53. U.S. Food and Drug Administration. 2010. Bacteriological analytical manual, appendix 2. Most probable number from serial dilutions. Available at: http://www.fda.gov/Food/FoodScienceResearch/ LaboratoryMethods/ucm109656.htm. Accessed 16 November 2015.

54. U.S. Food and Drug Administration. 2013. Bacteriological analytical manual, chap. 10. Detection and enumeration of Listeria monocytogenes in foods. Available at: http://www.fda.gov/Food/ FoodScienceResearch/LaboratoryMethods/ucm071400.htm. Accessed 22 October 2015.

55. U.S. Food and Drug Administration. 2016. FY 2014-2016 microbiological sampling assignment summary report: raw milk cheese aged 60 days. Available at: http://www.fda.gov/downloads/Food/ ComplianceEnforcement/Sampling/UCM512217.pdf. Accessed 16 August 2016.

56. U.S. Food and Drug Administration, Center for Food Safety and Applied Nutrition and U.S. Department of Agriculture, Food Safety and Inspection Service. 2003. Quantitative assessment of relative risk to public health from foodborne Listeria monocytogenes among selected categories of ready-to-eat foods. Available at: http://www. fda.gov/Food/FoodScienceResearch/RiskSafetyAssessment/ ucm183966.htm. Accessed 22 October 2015.

57. U.S. Food and Drug Administration, Center for Food Safety and Applied Nutrition and Applied Nutrition and U.S. Department of Agriculture, Food Safety and Inspection Service. 2013. Interagency risk assessment: Listeria monocytogenes in retail delicatessens. Available at: http://www.fda.gov/downloads/Food/ FoodScienceResearch/RiskSafetyAssessment/UCM370226.pdf. Accessed 22 October 2015.

58. U.S. Food and Drug Administration and Health Canada. 2015. Joint FDA/Health Canada quantitative assessment of the risk of listeriosis from soft-ripened cheese consumption in the United States and Canada. Available at: http://www.fda.gov/Food/ FoodScienceResearch/RiskSafetyAssessment/ucm429410.htm. Accessed 22 October 2015.

59. Varma, J. K., M. C. Samuel, R. Marcus, R. M. Hoekstra, C. Medus, S. Segler, B. J. Anderson, T. F. Jones, B. Shiferaw, N. Haubert, M. Megginson, P. V. McCarthy, L. Graves, T. Van Gilder, and F. J. Angulo. 2007. Listeria monocytogenes infection from foods prepared in a commercial establishment: a case-control study of potential sources of sporadic illness in the United States. Clin. Infect. Dis. 44:521-528.

60. Voetsch, A., F. Angulo, T. Jones, M. Moore, C. Nadon, P. McCarthy, B. Shiferaw, M. Megginson, S. Hurd, B. Anderson, A. Cronquist, D. Vugia, C. Medus, S. Segler, L. Graves, R. Hoekstra, and P. Griffin. 2007. Reduction in the incidence of invasive listeriosis in Foodborne Diseases Active Surveillance Network sites, 1996-2003. Clin. Infect. Dis. 44:513-520.

61. Wallace, F. M., J. E. Call, A. C. S. Porto, G. J. Cocoma, The ERRC Special Projects Team, and J. B. Luchansky. 2003. Recovery rate of Listeria monocytogenes from commercially prepared frankfurters during extended refrigerated storage. J. Food Prot. 66:584-591. 